TOPICAL REVIEW

\title{
Microfluidics for flow cytometric analysis of cells and particles
}

\author{
Dongeun Huh ${ }^{1}$, Wei Gu ${ }^{1,2}$, Yoko Kamotani ${ }^{1}$, James B Grotberg ${ }^{1}$ \\ and Shuichi Takayama ${ }^{1,3}$ \\ ${ }^{1}$ Department of Biomedical Engineering, University of Michigan, Ann Arbor, MI 48109-2055, \\ USA \\ ${ }^{2}$ Department of Chemical Engineering, University of Michigan, Ann Arbor, MI 48109-2136, \\ USA \\ ${ }^{3}$ Department of Macromolecular Science and Engineering, University of Michigan, Ann Arbor, \\ MI 48109-1055, USA \\ E-mail: takayama@umich.edu
}

Received 17 August 2004, accepted for publication 6 December 2004 Published 1 February 2005

Online at stacks.iop.org/PM/26/R73

\begin{abstract}
This review describes recent developments in microfabricated flow cytometers and related microfluidic devices that can detect, analyze, and sort cells or particles. The high-speed analytical capabilities of flow cytometry depend on the cooperative use of microfluidics, optics and electronics. Along with the improvement of other components, replacement of conventional glass capillary-based fluidics with microfluidic sample handling systems operating in microfabricated structures enables volume- and power-efficient, inexpensive and flexible analysis of particulate samples. In this review, we present various efforts that take advantage of novel microscale flow phenomena and microfabrication techniques to build microfluidic cell analysis systems.
\end{abstract}

Keywords: flow cytometry, microfluidics, microfabrication, cell analysis, cell separation

\section{Introduction}

Flow cytometry is the measurement of various physicochemical characteristics of suspended cells. The procedure is typically performed in combination with the use of fluorescent probes that stain cellular components or functions (Shapiro 1995). Using a microfluidic system that directs a high-speed single-file stream of cells to a focused laser beam in a glass capillary tube, flow cytometers capture light scattering at different angles and fluorescence emissions at several wavelengths for each individual cell (figure 1(a)). Detected light signals are collected by a 

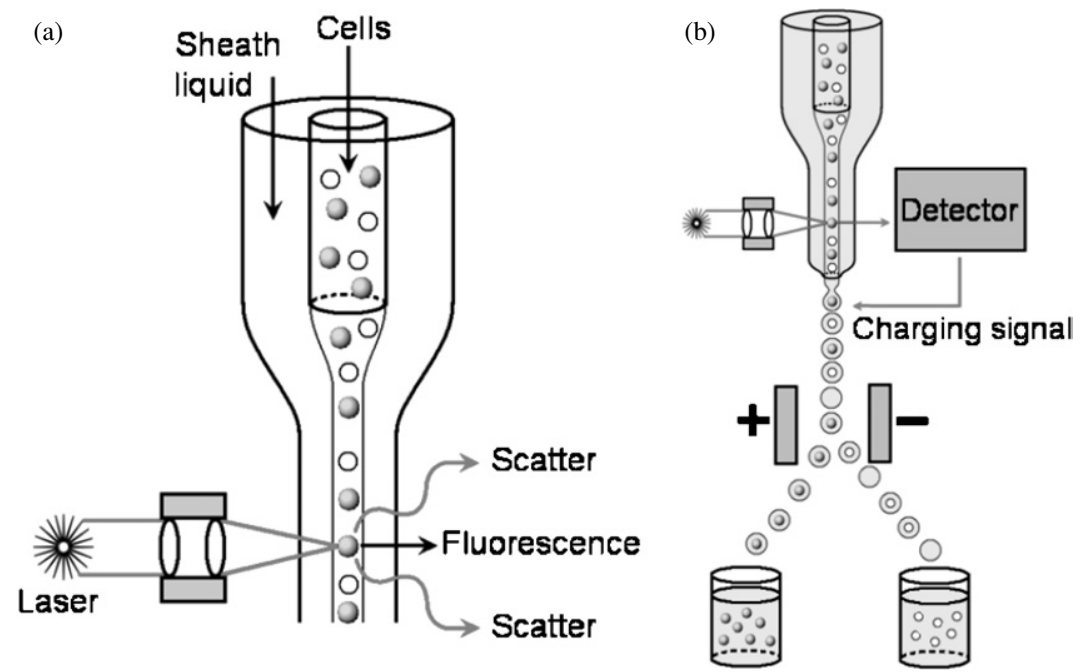

Figure 1. Schematic diagrams of (a) sample detection and (b) fluorescence-activated sorting in conventional low cytometry. (a) Cells are injected into the core of a sheath flow and confined to a narrow single-file stream by hydrodynamic focusing. As fluorescent labeled cells flow past a focused laser beam, they generate light scattering and fluorescence emission measured by optics and electronics. (b) Following optical detection of cells stained with fluorescent dye, the mechanical vibration of a nozzle tip at the end of a capillary tube generates droplets encapsulating cells. The droplets are selectively charged depending on the presence of labeled cells and deflected by an electric field to different collectors.

series of optical systems and processed by data-analysis electronics to measure morphological, biochemical and functional properties of cells such as size, shape, DNA content, cell surface markers, cell cycle distribution and viability. Such combined implementation of microfluidics, optics and electronics in modern flow cytometers provides a robust platform to quantify multiple characteristics of sample populations (e.g. cells, viruses, bacteria, yeast, aerosol particles, microbeads) simultaneously at high rates (up to approximately 25000 cells s$^{-1}$ ). For the past three decades, advances in precision technologies, dye synthesis and high-speed data-handling techniques have exerted synergistic effects on flow cytometry, bringing this powerful analytical tool into routine clinical and laboratory use in the field of cell/molecular biology (Harding et al 2000, Boeck 2001), disease diagnostics (Stein et al 1992, Fenili and Pirovano 1998), immunology (Gabriel and Kinermann 1995, Garratty and Arndt 1999), genetics (Wedemeyer and Potter 2001) and environmental monitoring (Dubelaar and Gerritzen 2000).

Modern flow cytometers boast the ability to measure five different parameters (multiple fluorescence colors and morphological features) routinely and up to as many as ten parameters or more on each cell (Steinkamp et al 1973, Roederer et al 1997). This enables the identification of homogeneous subpopulations within heterogeneous populations, making flow cytometry advantageous over other detection instruments such as spectrofluorimeters in which quantitative measurements are based on the analysis of entire populations. In addition to detection and enumeration, some flow cytometers permit the separation and isolation of cells without loss of viability, or particle purification without loss of characteristic structure (Horan and Wheeless 1977). The most commonly used method for sorting is the stream-in-air system in which a continuous liquid stream of cells emerging from a nozzle is converted into droplets containing single cells by mechanical vibration of the nozzle tip (figure 1(b)). Upon formation, the droplets are electrically charged depending on whether the cell they contain 
matches predetermined parameters such as fluorescence intensity. Charged droplets are then deflected by a strong electric field into a collecting container that separates them from other droplets. Using this method, modern commercial flow cytometers can sort up to 10000 cells s$^{-1}$ without affecting cell viability (Peters et al 1985, Boeck 2001). The analytical capabilities of flow cytometry are also finding increasing applications in characterizing molecules and large biological particles. Through different staining techniques and minor modifications of conventional flow cytometry, it is possible to detect receptor/antigen expression on cell surfaces (Jett et al 1981, Fornas 2002), carbohydrates (Duijndam and van Duijn 1988), lipids (Maczek et al 1996, Streicher et al 1999), cholesterol (Hassall 1992, Hassall and Graham 1995), proteins (Crissman et al 1981, 1985), ions (Minta and Tsien 1989, Meuwis et al 1995), chromosomes (Gray et al 1975, 1987), DNA/RNA (Darzynkiewicz et al 1999) as well as to analyze and isolate large objects such as islet cells (Gray et al 1989) or embryoid bodies from embryonic stem cells (Bohlen et al 2004).

Although conventional state-of-the-art flow cytometry systems provide rapid and reliable analytical capacities, they are still overall bulky, expensive and mechanically complex. Also, the operation of flow cytometers often suffers from the need for specialized personnel, multiple sample pre-treatment steps and a high volume requirement of the sample to be analyzed. Over the past decade, the drawbacks of conventional flow cytometers coupled with an increased need for sophisticated cellular analyses have motivated efforts to take advantage of microfabrication technologies and advanced microfluidics to achieve smaller, simpler, more innovative and inexpensive instrumentation. The use of microfluidics and microfabrication opens new opportunities to incorporate volume-efficient solid-state optics more easily with higher precision and to develop novel fluid/particle handling and sorting schemes (Stone et al 2004). It also confers the flexibility of integrating flow cytometry with other microfluidic cell manipulation and analysis systems that facilitate sample preand post-treatment as well as enable further analysis to extract additional information. The cost and complexity of fabricating fluidic components that are traditionally made of glass can be reduced by using materials such as inexpensive polymers. The increasing need for simple and small instrumentation resulted in the development of flow cytometers with enhanced portability for on-site sample measurements. A reduction in volume required to make the whole system smaller is often achieved by using solid-state optics. Currently, there are a number of commercially available portable flow cytometers that are easy to use and optimized for HIV screening and monitoring (http://www.partec.de), complete blood count measurements (Weigl et al (2001), http://www.micronics.net/), marine/fresh water analysis (Dubelaar et al 1999, Dubelaar and Gerritzen 2000), and cell culture monitoring and cell screening assays (http://www.guavatechnologies.com). In order to provide an overview of these and other approaches, here we present recent efforts to develop microfluidics for flow cytometers and other microscale flow-based cell analysis systems. The focus of this review lies in the development of microfluidic systems that are not based on glass capillaries and use microfabricated structures. Other components of flow cytometry such as optics will be discussed mainly in the context of emphasizing or verifying the novelty and functionalities of fluidic systems. Although automation and sophistication of modern flow cytometers are attributed to complex data-handling electronics, this topic is beyond the scope of this review (for an overview of flow cytometer electronics, see, for example, Snow (2003)).

\section{Background}

Establishing optimal fluid flows in flow cytometry, where cells are hydrodynamically focused into a single-file stream, requires precise fabrication. Here, we discuss the construction of 
various flow chambers, as well as pumps and switches used to establish the fluidics in these systems.

\subsection{Fabrication of fluidic components}

Manufacturing flow chambers for flow cytometers requires the fabrication of flow tubes and sample injectors that have dimensions on the order of tens to hundreds of micrometers. We briefly describe three general methods to create flow cytometers: (i) those for traditional flow cytometers, (ii) solid-state micromachining and (iii) molding.

2.1.1. Traditional flow cytometers. Flow cytometers that contain flow chambers or cuvettes can be made in several ways. Older designs involve pulling glass tubes into thinner tubes suitable for a flow chamber. A high-gauge blunt needle can then be inserted into the middle of the tube as an injector while sheath fluid moves forth around the injector. More recently, manufacturers have used double opening, quartz cuvettes, better suited for optical interrogation. Quartz has high UV transmission, low coefficient of thermal expansion and chemical resistance. The quartz cuvettes need to be carefully fused and polished for the best results, making them expensive.

2.1.2. Micromachining. More recently, flow cytometers have been fabricated using micromachining techniques derived from the computer chip industry. The two main sets of micromachining methods are surface (or additive) micromachining, where thin layers of new material are added to a substrate, and wet bulk (or subtractive) micromachining, where a substrate is etched.

Surface micromachining builds up patterned layers of photoresist. A glass chrome mask determines this pattern by selectively permitting UV light through to induce or prevent spincoated photoresist curing. Negative photoresist cures or hardens with UV exposure, whereas positive photoresist cures without UV exposure. Uncured photoresist can subsequently be washed away with a developer solution to expose the defined channel architecture as positive outcroppings.

In wet bulk micromachining, patterned photoresists are used as masks for etching grooves into silicon or glass substrates. Etchant diffuses to, reacts with, and diffuses away with the etched material from the exposed substrate during etching. Etching can be performed isotropically or anisotropically, depending on the etchant (figure 2(a)). Isotropic etching is limited by diffusion and etches the substrate in all crystallographic directions, creating a rounded groove. Examples of isotropic etchants include various combinations of HF, other strong acids, acetone and $\mathrm{KOH}$ with alcohols. Anisotropic etching dissolves substrate material in select directions faster than others depending on the direction of the crystal lattice of the substrate. The procedure produces features with sharp edges such as pyramidal shapes or $\mathrm{V}$-shaped grooves. Examples of anisotropic etchants for silicon substrates include $\mathrm{KOH}$, ethylenediamine pyrocatechol and tetramethyl ammonium hydroxide.

2.1.3. Soft lithography. In soft lithography, microfluidic channels are replicated by casting pre-polymer against a master mold, which are typically created by a variation of contact photolithography that uses inexpensive and rapidly prepared high-resolution transparency masks in place of chrome masks (Duffy et al 1998). The master mold has positive relief structures that hollow out negative relief structures in the cured (hardened) polymer cast against it. The polymer structures with open channel features are then sealed against flat surfaces such as plastic, glass or elastomer to provide closed channel systems (figure 2(b)). 
(a)

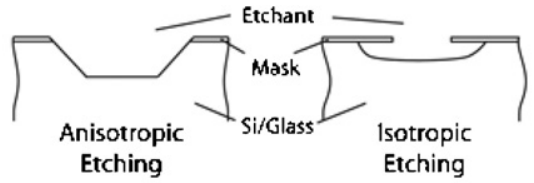

Fabricate master by rapid prototyping
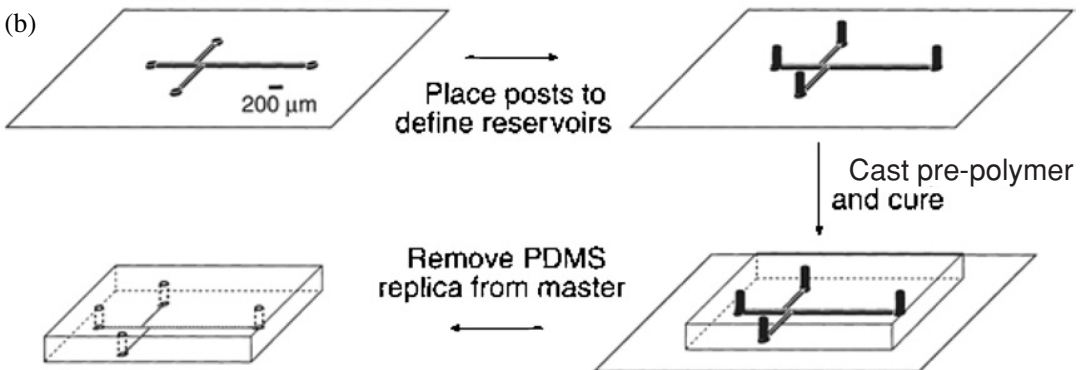

Remove PDMS replica from master
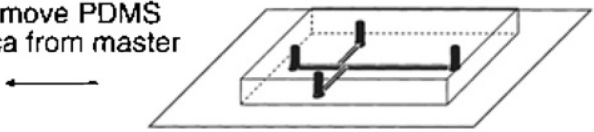

Oxidize PDMS replica and flat in plasma and seal

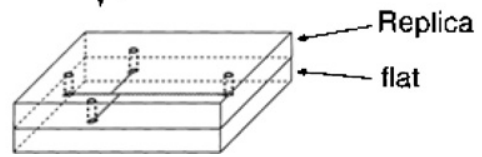

Figure 2. Schematic diagrams of (a) etching and (b) additive micromachining in conjunction with soft lithography. (a) Left: anisotropic etching degrades certain directions faster than others, creating sharp angles and flat surfaces. Right: isotropic etching is difusion limited and will etch the silicon/glass substrate in a rounded manner. (b) Soft lithography involves creating a photoresist master using contact photolithography, a form of additive micromachining, and curing silicone rubber (PDMS) on top to replicate channel features.

The most popular elastomer, poly(dimethylsiloxane) (PDMS), enjoys several advantages as a material for fabricating microfluidic systems (Whitesides et al 2001). PDMS is composed of cross-linked siloxanes with the backbone $\left(-\mathrm{Si}\left(\mathrm{CH}_{3}\right)_{2}-\mathrm{O}-\right)$. The material is soft compared to silicon or glass, but is a moderately stiff polymer (Young's modulus $\sim 1 \mathrm{MPa}$ ). The elastomer stiffness can be adjusted by the degree of cross linkage, which is controlled by the amount of curing agent added to the base chain monomers (typically in a 1:10 weight ratio). PDMS is optically clear making integration of on-chip or external optical devices convenient. Finally, this material, which is intrinsically hydrophobic, can be chemically treated to become hydrophilic.

\subsection{Pumps and switches}

Different pumping and switching schemes exist for flow cytometers. In traditional flow cytometers, flow is driven either by balancing pneumatic pressures on sheath fluid and injection sample, or by injecting at a constant flow rate with a syringe pump. In non-traditional flow cytometers, pumping and switching mechanisms can be split into two categories: (i) passive, where no external power is applied, and (ii) active, where an external power source is used.

Passive pumps are driven by gravity, capillary force or evaporation. Liquid can be steadily delivered through gravity when a height difference is maintained. This was performed using 
inlet and outlet water levels that move laterally while being held up by capillary forces within horizontally placed reservoirs (Zhu et al 2004). Steady flow can also be maintained for days and weeks through suction generated by the evaporation of a liquid using adsorption materials (Effenhauser et al 2002). Another pump used the surface tension of a small drop placed at an inlet to drive fluid flows (Walker et al 2002).

Several actively driven plumbing systems have been developed, although we will only describe three general subcategories here. One of the simplest is direct pneumatic pressure from sources such as external air/hydraulic lines or constant flow syringe pumps, which are both used for traditional flow cytometers. The second fluidic control, electrokinetic flow, involves setting up an electric field across ionic buffer-filled channels. Interaction between ions, the negatively charged channel surface (deprotonated $\mathrm{SiOH}$ groups), and the controlled macroscopic electric field can translate fluid through selected channels (Fu et al 1999). Another type of fluidic control involves deforming the soft material surrounding channels (Fu et al 2002). This is typically done with PDMS in soft lithography or with parylene in micromachined channels. A nearby mechanical force or pneumatic/hydraulic pressure can be used to squeeze and collapse soft channels (Unger et al 2000, Yang et al 1998). Pneumatic valves and the associated peristaltic pumps have been fabricated at high densities to essentially provide a complex microfluidic plumbing network (Thorsen et al 2002). We have designed a medium density, mechanically actuated plumbing system using commercial refreshable Braille displays (Futai et al 2004, Gu et al 2004). The advantages of channel deformation-based methods include robust and complex fluidic control without regard to the ionic or chemical properties of the moving fluid, and in the case of using Braille displays, provide a readily portable and convenient off-shelf system. Finally, electrowetting can be used to switch flow direction by switching the surface between being hydrophobic and hydrophilic (Huh et al 2003). When a voltage difference is applied to a hydrophobic surface, the wettability of the surface in the presence of liquid can be altered. Thus fluid flow can be influenced into different directions using this transient change in wettability.

\section{Novel microfluidics for flow cytometric analysis of cells/particles}

The goal of incorporating new types of microfabricated flow channel systems that replace glass capillary-based flow chambers is to enable more precise and rapid manipulation of cells and to take advantage of different driving forces for controlling fluid flows. It also allows for more compact optics and volume-efficient on-chip sample detection through physical registration and integration of small solid-state optical components in close proximity to the fluidic system. In this section, we provide an overview of microfluidic sample transport and manipulation systems that are combined with on-chip and/or off-chip optics to perform detection/enumeration and sorting of cells or particles.

\subsection{Cell/particle detection and enumeration systems (see table 1)}

3.1.1. Microfluidics for sample transport. In conventional flow cytometers, a sheath liquid surrounds the sample flow to align cells in single file along the center of the stream and to prevent clogging of capillary tubes with cell aggregates. This hydrodynamic focusing is critical for reliable optical analysis of cells and is an important issue for development of microfabricated flow cytometer channel systems. Microfabricated channel structures with multiple laminar flow configurations are capable of stably delivering samples to a detection area with higher accuracy and better flow control compared to conventional glass capillary-based fluidic systems. The advantages of using microfabrication include the ability to create desired 
Table 1. Summary of microfabricated flow cytometers.

\begin{tabular}{|c|c|c|c|c|c|}
\hline $\begin{array}{l}\text { Flow pumping } \\
\text { method }\end{array}$ & $\begin{array}{l}\text { Demonstrated detection } \\
\text { rate or mean flow } \\
\text { speed/rate }\end{array}$ & Material & $\begin{array}{l}\text { Cross-sectional size } \\
\text { of detection channel }\end{array}$ & Sheath fluid & Reference \\
\hline Syringe pump (positive pressure) & $\begin{array}{l}\sim 1 \mathrm{~m} \mathrm{~s}^{-1} \\
10 \mathrm{~m} \mathrm{~s}^{-1} \\
0.05-1.4 \mathrm{~mm} \mathrm{~s}^{-1} \\
100 \mathrm{particles} \mathrm{s}^{-1} \\
30 \mathrm{~nL} \mathrm{~s}^{-1} \\
50 \mathrm{~nL} \mathrm{~s}^{-1} \\
5 \mathrm{~mm} \mathrm{~s}^{-1} \\
500 \text { particles s}^{-1} \\
0.05 \mu \mathrm{L} \mathrm{min}^{-1}\end{array}$ & $\begin{array}{l}\text { Silicon and glass } \\
\text { Fused silica (quartz) } \\
\text { PMMA } \\
\text { Glass, polyimide and PDMS } \\
\text { Plastic } \\
\text { Silicon and glass } \\
\text { Silicon and glass } \\
\text { PDMS } \\
\text { PMMA, glass, SU-8 }\end{array}$ & $\begin{array}{l}300 \times 100 \mu \mathrm{m} \\
\text { Radius }=125 \mu \mathrm{m} \\
2.4 \mathrm{~mm} \times 38.12 \mu \mathrm{m} \\
20 \times 40 \mu \mathrm{m} \\
100-3000 \times 50-400 \mu \mathrm{m} \\
20-25 \times 14-17 \mu \mathrm{m} \\
\text { Channel depth }=50-200 \mu \mathrm{m} \\
300 \times 100 \mu \mathrm{m} \\
100 \times 25 \mu \mathrm{m}\end{array}$ & $\begin{array}{l}\text { Liquid } \\
\text { Liquid } \\
\text { Liquid } \\
\text { Liquid } \\
\text { Liquid } \\
\text { No sheath } \\
\text { No sheath } \\
\text { Liquid } \\
\text { Liquid }\end{array}$ & $\begin{array}{l}\text { Miyake et al }(1997) \\
\text { Sobek et al }(1993) \\
\text { Lee } \text { et al }(2001,2003) \\
\text { Gawad et al }(2001) \\
\text { Weigl } \text { et al }(2001) \\
\text { Altendorf } \text { et al }(1997) \\
\text { Chau } \text { et al }(1999) \\
\text { Tung } \text { et al }(2004) \\
\text { Lee } \text { et al }(2001,2003)\end{array}$ \\
\hline Pressurized air (positive pressure) & $50-200 \mathrm{~nL} \mathrm{~s}^{-1}$ & Plastic & Unknown & Liquid & Cabuz et al (2002) \\
\hline Vacuum pump (negative pressure) & $\begin{array}{l}\text { Unknown } \\
2-4 \text { particles s }^{-1}\end{array}$ & $\begin{array}{l}\text { PDMS and glass } \\
\text { Glass }\end{array}$ & $\begin{array}{l}100 \times 40 \mu \mathrm{m} \\
75 \times 25 \mu \mathrm{m}\end{array}$ & $\begin{array}{l}\text { Liquid } \\
\text { Liquid }\end{array}$ & $\begin{array}{l}\text { Chung et al (2003) } \\
\text { Chan et al (2003) }\end{array}$ \\
\hline $\begin{array}{l}\text { Combination of syringe and } \\
\text { vacuum pumps }\end{array}$ & $\sim 1 \mathrm{~m} \mathrm{~s}^{-1}$ & PDMS & $300 \times 100 \mu \mathrm{m}$ & Air & Huh et al $(2002,2003)$ \\
\hline Electro-osmotic flow & $30-85$ particles s $^{-1}$ & Glass & $50 \times 20 \mu \mathrm{m}$ & Liquid & McClain et al $(2001,2003)$ \\
\hline
\end{tabular}


structures rapidly and inexpensively, and to obtain optimized channel geometries that are difficult or impossible to fabricate using conventional glass machining techniques. Miyake et al (1997) reported the development of a multilayered sheath flow chamber that can generate a three-dimensionally focused narrow stream of fluorescent dyes and micrometer-sized particles; a three-dimensionally focused stream is surrounded by sheath liquid on all sides, whereas a two-dimensionally focused stream is exposed to sheath flow on just two sides and contacts the top and bottom channel surfaces. The channel system was formed by the lamination of five different silicon and glass plates defining the three-dimensional geometry of a sample injection nozzle and a detection microchannel. Through viscous flow analysis and careful channel design, they optimized the flow conditions and the channel structure to achieve a stable sample stream having widths of a few tens of micrometers. The design also allowed use of smaller pressure drops across the channel system to generate the required high-speed flows due to the much shorter channel length compared to the long glass capillary tubes $(2.5-4 \mathrm{~cm})$ used in conventional flow cytometers. A similar system for flow cytometric analysis was created on quartz wafers by Sobek et al (1993). The micromachined flow cytometer consists of two symmetric parts made of fused silica that are bonded together to define the geometry of a sheath flow chamber and a detection channel. Hydrodynamic focusing is achieved by the injection of a sample stream into the core of sheath flows in a converging sheath chamber. Using this system, they demonstrated the generation of a thin core stream $(\sim 10 \mu \mathrm{m})$ with a high mean velocity (up to $10 \mathrm{~m} \mathrm{~s}^{-1}$ ).

Hydrodynamic focusing was theoretically and experimentally studied in detail by Lee et al (2001) in a microfabricated sample injection system in which a stream of sample is injected through a small inner nozzle into a converging outer nozzle with sheath flows enveloping the core stream from the sides (figure 3(a)). Potential flow theory and numerical simulation using the finite volume method showed that two-dimensional hydrodynamic focusing produces a confined sample stream with a width smaller than $10 \mu \mathrm{m}$ when the point of sample injection from the inner nozzle is located in the middle of the outer nozzle and the ratio of sheath flow rate to sample flow rate is increased. They also fabricated an inexpensive flow chamber made of poly(methylmethacrylate) (PMMA) using a hot embossing method, and demonstrated hydrodynamic focusing of liquid streams containing dye solution that were as narrow as $10 \mu \mathrm{m}$. The difference between two- and three-dimensional hydrodynamic focusing in terms of sample detection was investigated by Chung et al (2003). Two- and three-dimensionally focused liquid streams were achieved by planar and two-level channel geometries made of poly(dimethylsiloxane) (PDMS), respectively. Different cross-sectional shapes of focused sample flows generated by different channel geometries and flow rates were studied using numerical simulation and laser scanning confocal microscopy. In laser-induced fluorescence measurements of microbeads, two-dimensional hydrodynamic focusing was found to cause broadening of signal intensity by allowing sample particles to be distributed more widely in the vertical direction, whereas three-dimensional focusing yielded more normalized and stable detection signals.

Using a networked microfluidic channel system with automated sample staining capabilities, Chan et al (2003) demonstrated a flow cytometric assay of protein expression and apoptosis in human primary cells. In their setup illustrated in figure 3(b), primary cells are moved by pressure-driven flow to different areas of a glass microchannel network for sample staining and detection. They used disposable glass chips having microchannel structures fabricated by wet chemical etching and anodic bonding of glass wafers. To make cells pass through a detection spot in single file, the system incorporates hydrodynamic focusing in which a stream of cells converges with sheath flow at a Y-shape junction. The cells are then focused to one sidewall of the microchannel by sheath flow driven at a higher flow rate than the sample 


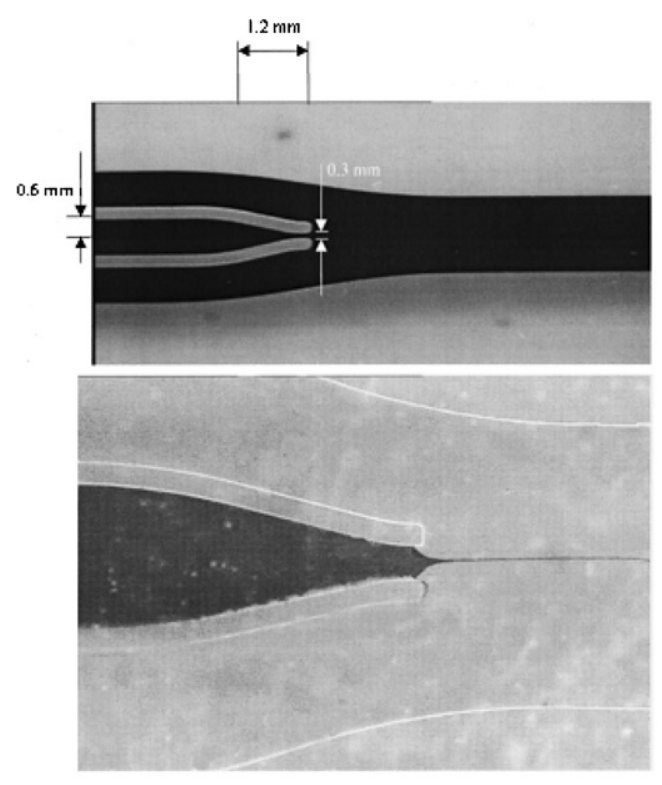

(a)

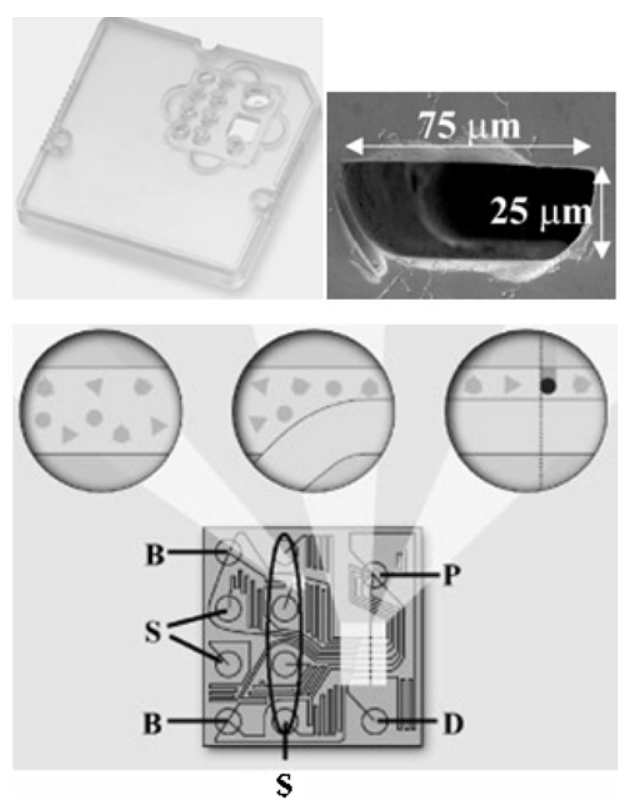

(b)

Figure 3. (a) Microfabricated sample focusing chamber made of PMMA using hot embossing (top) and hydrodynamic focusing of a dye-containing sample stream by water sheath flows (bottom). The hydrodynamic focusing based on this converging nozzle shape generates sample streams as thin as $10 \mu \mathrm{m}$. Reprinted with permission from Lee et al. (b) A glass microfluidic chip for mammalian cell assays. A network of glass microchannels (cross-sectional shape is shown in top-right insert) is glued into a plastic holder or automated low control by positive and negative pressures applied to multiple inlet/outlet ports (top left). A sample stream is transported to diferent locations or on-chip staining and optical detection. B: buffer wells, S: sample wells, P: priming well, D: reference dye well. Reprinted with permission from Chan et al (2003).

stream. During sample process and analysis, fluid flows in all channels are tightly regulated by a vacuum applied to multiple inlet and outlet ports, and the system uses two independent light sources exciting two different wavelengths for detection of proteins or fluorescent dyes staining live or dead cells. Using normal human dermal fibroblasts (NHDFs), they showed that the system is capable of performing assays with low reagent and cell consumption. They demonstrated a successful flow cytometric analysis of the up-regulation of E-selectin expressed by interleukin- $1 \beta$ in human umbilical vein endothelial cells (HUVECs), induction of CD3 by phorbol-12-myristate-13-acetate in freshly prepared human peripheral blood lymphocytes, and staurosporine-induced apoptosis in HUVECs and NHDFs. Cabuz et al (2002) reported a highly miniaturized and power-efficient flow control system for a portable flow cytometer. They used electrostatically actuated silicon microvalves and highly sensitive glass-based thermal flow sensors to produce pressure-driven flows with little $(\sim 3 \%)$ pulsatility in a closed-loop flow channel system. They integrated the flow sensing and valving system with a pressure pump to build a complete fluidic module for a portable flow cytometer that generates a stable $15 \mu \mathrm{m}$ wide sample core stream by hydrodynamic focusing.

Gawad et al (2001) demonstrated the successful use of spectral impedance measurements for on-chip cell detection and counting. The analyzer measures impedance signals, which are correlated with cell size and type, as hydrodynamically focused cells flow by electrodes embedded in glass channel walls and interact with an applied AC electric field. The 
measurements are based on the delivery of focused cells to a sensing area with multiple electrodes by laminar streams and the differential variation in impedance between two adjacent electrodes fabricated at the length scale of cells/particles to be analyzed. The combined electronics allow simultaneous impedance measurements at multiple high frequencies, permitting detection and counting at the rate of over 100 samples per second. The system was verified to be able to distinguish $8 \mu \mathrm{m}$ particles with lower impedance signals from $5 \mu \mathrm{m}$ particles generating higher signals. Also, they demonstrated the differentiation of subpopulations in the mixture of normal erythrocytes and erythrocyte ghost cells, illustrating the capability of identifying different cell types using the system.

Flow cytometer microchannels can be integrated with other sample processing steps such as chemical reactors, diluters and mixers, interconnected by a network of microfluidic channels as shown in cytometric system developed by Weigl et al (2001). In their integrated device made of multiple layers of plastic laminates, a whole blood sample injected into the system is first split to three different flow chambers in a parallel manner to extract and pre-treat different subpopulations of blood. In the first chamber, hemoglobin extracted from lysed red blood cells in a chemical diffuser structure is converted into cyanmethemoglobin for optical detection. In the second chamber, the whole blood sample is diluted and hydrodynamically/geometrically focused for counting red blood cells and platelets based on light scattering. In the third chamber, diluted whole blood is lysed with a 'soft' lyse to visualize only white blood cells for flow cytometric detection. The ability of the multi-compartment fluidic system to lyse cells in a selective and real-time manner and to analyze resulting samples using flow cytometry facilitates on-chip hematological analysis.

Microfluidic flow cytometry of $E$. coli was reported by McClain et al (2001). The microfluidic system has a flow chamber consisting of four microchannels intersecting perpendicular to each other. At the intersection, bacterial cells are electrokinetically transported and focused into a thin stream along the center for single-cell scatter and fluorescence detection using a microscope coupled with a photomultiplier tube. In order to minimize cell adhesion and to prevent electro-osmotic flow, the channels were coated with poly(dimethylacrylamide) (PDMA). Detection of scattering and fluorescence of $E$. coli labeled with Syto15 permitted quantitative measurements on cell size and the amount of nucleic acid in the cells. A viability assay with on-chip staining of bacterial cells showed that most of the cells remained alive in the applied electric field used for electrokinetic fluid transport. Fluorescently labeled antibody specific to $E$. coli could be used to optically detect the bacteria with a throughput of 30-85 cells s ${ }^{-1}$.

Although sheath liquid-based hydrodynamic focusing serves as a standard technology in conventional and microfabricated flow cytometers, it requires a large amount of sheath liquid to process a very small amount of sample (up to $1 \mathrm{~L}$ of sheath liquid for $1 \mathrm{~mL}$ of sample), preventing further reduction in the size and volume of the whole system. It also needs continuous pumping of sheath liquid at high flow rates to generate a thin sample stream. In order to address the shortcomings of liquid sheath flow-based flow cytometers, new types of microfluidic systems without any need for sheath liquid or with use of different sheath fluid have been developed.

Huh et al (2002) demonstrated the use of ambient air as an alternative sheath fluid in a stable and disposable air-liquid two-phase microfluidic system that can perform microscopebased cell/particle detection and enumeration. Through an engineering of the wetting properties of microchannel surfaces made of poly(dimethylsiloxane) (PDMS) as well as the manipulation of fluid mechanical parameters, the system generates a thin $(15-100 \mu \mathrm{m})$ and high-speed (up to $1 \mathrm{~m} \mathrm{~s}^{-1}$ ) liquid stream transporting cells or microbeads focused by air-sheath flows in a rectangular microfluidic channel (figure 4(a)). They studied the effect of surface 


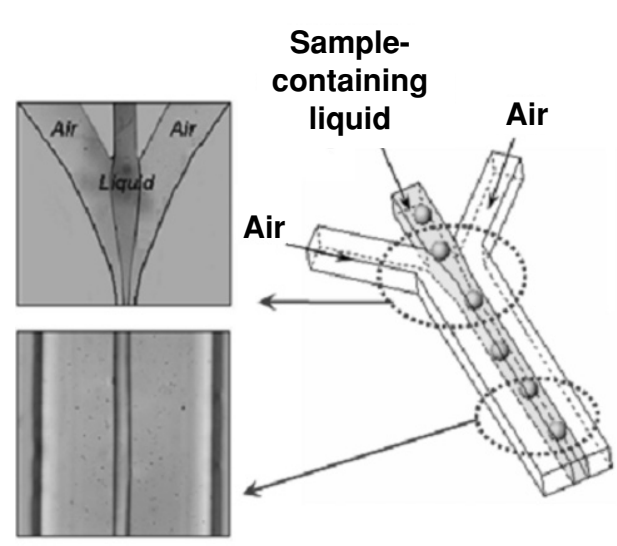

(a)
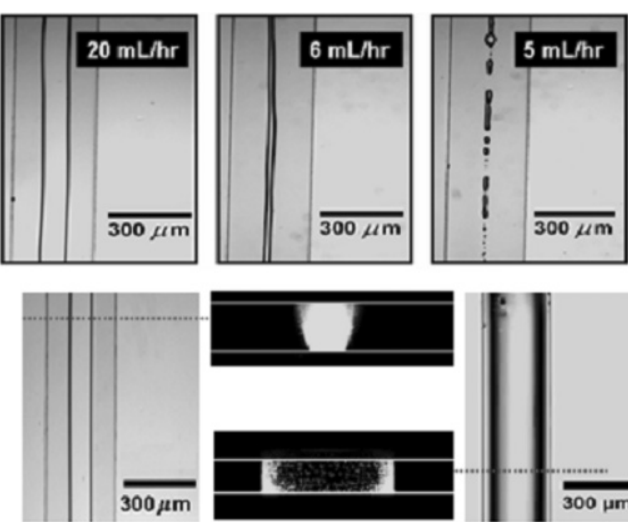

Hydrophobic channel

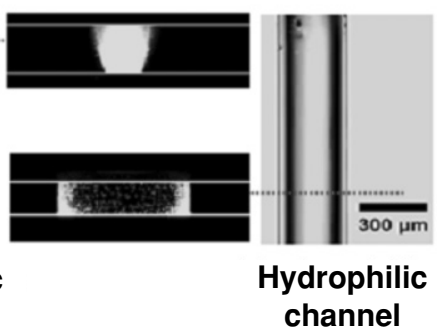

(b)

Figure 4. (a) Air-liquid two-phase microfluidic system that generates a stable high-speed stream of cells in a hydrophobic PDMS microchannel. Injected liquid is stably focused by air streams in a rectangular microchannel. (b) Effect of liquid flow rate and surface wettability on the shape and stability of liquid streams. At a fixed air flow rate, as liquid flow rate decreases, the liquid column becomes thinner and eventually breaks up into small droplets. In contrast to stable aerodynamic focusing in a hydrophobic PDMS microchannel, hydrophilic channel surfaces cause the liquid stream to spread to the sidewalls of microchannels. Cross-sectional shapes of flows were captured by confocal microscopy.

wettability on aerodynamic focusing under different fluid flow rates and optimized surface and flow conditions in which the air-liquid two-phase stratified flow becomes steady and stable, overcoming the intrinsic susceptibility of thin liquid column to gas-liquid two-phase instabilities (figure 4(b)). Using an inverted microscope and photomultiplier tube (PMT), they demonstrated detection and enumeration of microbeads and C2C12 myoblast cells.

Altendorf et al (1997) used a sheath-free transport of blood cells in a V-groove microchannel fabricated by anisotropic wet etching of silicon to perform differential blood cell counts. The width of the top of the V-shaped groove is $20-25 \mu \mathrm{m}$ and the constriction channel geometry allows the generation of a single-file stream of blood cells moving through the channel without the need for sheath fluid. Using optics based on a photomultiplier tube (PMT), photodiode detector and laser source, the measurements of light scattering signals caused by flowing blood cells in a diluted whole blood sample were taken. The results identified different cell populations such as red blood cells, platelets, lymphocytes, monocytes and granulocytes based on the intensity of scattering signals, showing the usefulness of the device for differential counting of blood cells.

The sheath-free flow cytometric system is found to be useful for monitoring biological fluids such as albumin in serum (Chau et al 1999). Chau et al designed a silicon microfluidic chamber coupled with a fiber-optic reflection probe to take reflection-absorption measurements. The system features a simple straight flow pathway for transport of biological fluids that do not require hydrodynamic focusing or sheath fluid and a bundle of optical fibers that emit and receive light signals. To characterize the system, they measured the absorbance spectra of a dye solution rinsing the microchannel to show that the sample could be rinsed out thoroughly in the module and that sample spectra were reproducible. Also, the coupling efficiency of light between the optical fibers was calculated and its optimal value was correlated 
with the depth of silicon microchannel and the thickness of glass forming the bottom floor of flow channel. Using this system and the dye Bromcresol Purple that specifically binds to albumin, they demonstrated a linearly increasing absorbance at $610 \mathrm{~nm}$ due to increased concentration of Bromcresol Purple at an elevated concentration of albumin.

A sheath-free sample transport system for portable flow cytometry was reported by Goix et al (2004). The commercialized portable flow cytometer (http://www.guavatechnologies. com) is featured by a microcapillary flow system in which the delivery of cells or microparticles to a detection location is achieved by a single liquid stream driven by a syringe pump. This system eliminates the need for hydrodynamic focusing of sample streams with sheath liquid by avoiding the use of highly concentrated samples (this is to prevent overlap of cells), by using a capillary tube with a small inner diameter that physically hinders multiple cells from entering the tube simultaneously, and by adjusting the optics to be more tolerant of slight differences in position of cells in the tube. Through the combination of a capillary with magnetic elements concentrically surrounding the tube, cells conjugated with magnetically charged dyes can also be focused along the center of the stream. By virtue of the fluidic design that does not require sheath fluid, the system allows the use of small sample volumes and produces small amounts of waste. Combined with laser-induced fluorescence and light scatter, this system has the capabilities of performing automated cell counting and viability assays, protein expression analysis and apoptosis analysis.

3.1.2. Optics for sample detection and enumeration. The use of microfabricated channel systems for the microfluidic transport of cells opens new opportunities for integrating optical waveguides and solid-state devices with the fluidics. Although not in a custom-designed microfabricated device, the concept of using solid-state optical systems in flow cytometry was demonstrated by Niehren et al (1995). They used a diode laser and a single photon counting avalanche diode (SPAD) combined with digital data acquisition system to detect and count fluorescent beads flowing in a square glass flow chamber at moderate rates. They achieved considerable volume reduction by using solid-state optical components (the whole device was only $50 \mathrm{~cm} \times 30 \mathrm{~cm} \times 15 \mathrm{~cm}$ ).

Tung et al (2004) also investigated the use of solid-state lasers and silicon-based PIN photodiode detectors combined with optical-fiber waveguides for multi-color laser excitation and fluorescence detection in a microfabricated flow cytometer made of poly(dimethylsiloxane) (PDMS) (figure 5). Using multiple angles of excitation and detection through the optical fibers inserted into the channel system at different angles, they studied multi-color excitation of sample particles at a single interrogation point and examined the ability of lock-in amplification techniques to increase the signal-to-noise ratio of PIN-based photodetector systems. The flow cytometric capability of this system was demonstrated by multi-color detection of hydrodynamically focused fluorescent particles and nucleic acid labeled fungus.

Lee et al (2003) proposed a novel approach to integrate optical waveguides with flow cytometer channel systems. Instead of inserting optical fibers through microfabricated notches, they developed a microfabrication method to embed optical waveguides made of photoresist (SU-8) coated by a thin layer of spin-on-glass (SOG). The seamless configuration of SU-8 and surrounding SOG layer increases the difference in refractive indices between core/wall interfaces and also enhances the light guiding efficiency by reducing dispersion loss. The optical waveguides were embedded into a flow cytometer channel having inner and outer nozzles to produce a thin (less than $10 \mu \mathrm{m}$ ) stream of particles. The integrated fluidic channeloptical waveguide system was coupled to a gas laser and avalanche photodiodes without any need for complex optical alignment. 


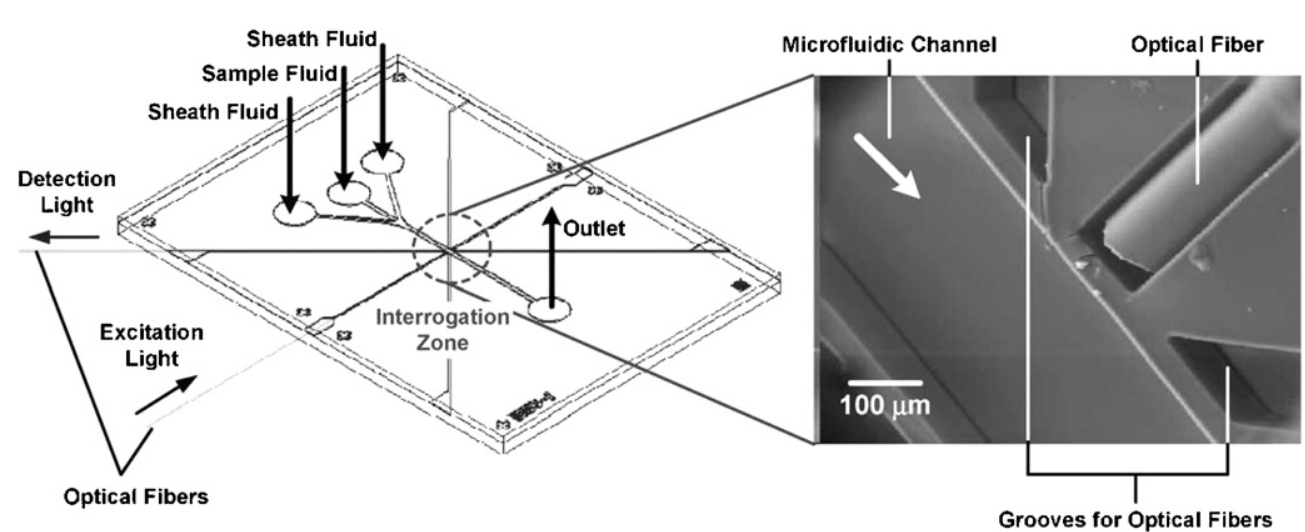

Figure 5. Microfabricated PDMS flow cytometer with embedded optical-fiber waveguides. Optical fibers are inserted close to a microfluidic channel through microfabricated grooves. Using solidstate lasers and PIN photodetectors, samples flowing in the observation zone are excited and detected at multiple angles, permitting multi-color sample detection. Reprinted with permission from Tung et al (2004).

Recent advances in optics for single molecular detection have also been adopted in flow cytometry (Ferris et al 2002). To overcome the limitations of conventional flow cytometers that are not optimized for detection of fluorescently labeled viruses, Ferris $e t$ al developed a single nanometric particle enumerator by combining a capillary microchannel with Ar-laserand PMT-based optical system that produces a diffraction-limited spot size of $\sim 0.5 \mu \mathrm{m}$ and a probe volume of $\sim 8 \mathrm{fL}$. This system detects single nanoparticles with a diameter as small as $26 \mathrm{~nm}$, is inexpensive to build compared to commercial flow cytometers, and does not require sophisticated detectors and electronics. They optimized this system for viral analysis and demonstrated rapid enumeration of adenovirus, respiratory syncytial virus and influenza virus. Compared to time-consuming standard viral analysis methods such as cell culture techniques, plaque assay or tunneling electron microscopy, this instrument has the capability of completing the analysis within one hour.

Zhong et al (2004) constructed a two-beam scan, two-channel detection, and two-photon excitation system that enables in vivo flow cytometry of fluorescently labeled cells/particles circulating in blood streams. Compared to one-photon excitation of conventional flow cytometry, the nonlinear property of multi-photon excitation processes can define a much smaller excitation volume and provide a higher signal-to-noise ratio due to the easy separation of fluorescence signals from the excitation source. For in vivo use of this detection system under pulsatile blood flow conditions, they used two laser beams to measure instantaneous flow speeds for normalization of signals. In vivo flow cytometry was demonstrated by injecting multi-color microbeads into the blood stream of a mouse and detecting two-photon excited fluorescence signals from a superficial blood vessel in the mouse ear.

\subsection{Microfluidic fluorescence-activated cell/particle sorting systems (see table 2)}

The most advanced feature of flow cytometry resides in its ability to sort cells at high speeds based on detected signals. This requires rapid and precise orchestration between different components of flow cytometry to selectively manipulate the movement of target samples in a liquid stream at single-cell resolution. Along with detection and enumeration, highspeed sorting based on fluorescence has been an important theme in the development of microfabricated flow cytometers. 
Table 2. Summary of microfabricated fluidic systems for fluorescence-activated sorting.

\begin{tabular}{|c|c|c|c|c|c|c|c|}
\hline $\begin{array}{l}\text { Sorting } \\
\text { mechanism }\end{array}$ & Method & $\begin{array}{l}\text { Flow } \\
\text { pumping }\end{array}$ & $\begin{array}{l}\text { Demonstrated } \\
\text { sorting throughput } \\
\text { or switching rate }\end{array}$ & Material & $\begin{array}{l}\text { Integrated } \\
\text { Optics }\end{array}$ & $\begin{array}{l}\text { Sheath } \\
\text { fluid }\end{array}$ & References \\
\hline \multirow[t]{3}{*}{ Hydrodynamic flow switching } & $\begin{array}{l}\text { Redirection of sample } \\
\text { streams by high-speed } \\
\text { valving (response time: } \\
0.26 \mathrm{~s} \text { ) }\end{array}$ & Syringe pump & $\begin{array}{l}\text { N/A (manual } \\
\text { flow switching) }\end{array}$ & $\begin{array}{l}\text { Silicon, } \mathrm{SU}-8 \\
\text { and glass }\end{array}$ & $\begin{array}{l}\text { Avalanche } \\
\text { photodiode }\end{array}$ & Liquid & $\begin{array}{l}\text { Kruger et al } \\
(2002)\end{array}$ \\
\hline & $\begin{array}{l}\text { Redirection of sample } \\
\text { streams by high-speed } \\
\text { pumping/valving } \\
\text { (response time: } 5 \mathrm{~ms} \text { ) }\end{array}$ & $\begin{array}{l}\text { Microfabricated } \\
\text { pumps/valves by } \\
\text { multilayer soft } \\
\text { lithography }\end{array}$ & 26-44 samples s ${ }^{-1}$ & PDMS & $\mathrm{N} / \mathrm{A}$ & No sheath & $\begin{array}{l}\text { Fu et al } \\
(1999,2002,2004)\end{array}$ \\
\hline & $\begin{array}{l}\text { Redirection of sample } \\
\text { streams by high-speed } \\
\text { valving (response } \\
\text { time: } 2.5 \mathrm{~ms} \text { ) }\end{array}$ & Syringe pump & $\sim 200$ samples s$^{-1}$ & $\begin{array}{l}\text { Silicon, gold } \\
\text { and glass }\end{array}$ & Waveguides & Liquid & Wolff et al (2003) \\
\hline \multirow[t]{2}{*}{$\begin{array}{l}\text { Electrokinetic } \\
\text { flow switching }\end{array}$} & $\begin{array}{l}\text { Redirection of sample } \\
\text { streams by reversed } \\
\text { electrokinetic flows }\end{array}$ & $\begin{array}{l}\text { Electro-osmotic } \\
\text { flow }\end{array}$ & $\sim 20$ samples s $^{-1}$ & PDMS & $\mathrm{N} / \mathrm{A}$ & Liquid & $\begin{array}{l}\text { Fu et al } \\
(1999,2002,2004)\end{array}$ \\
\hline & $\begin{array}{l}\text { Redirection of sample } \\
\text { streams by electrokinetic } \\
\text { injection }\end{array}$ & $\begin{array}{l}\text { Electro-osmotic } \\
\text { flow }\end{array}$ & $\begin{array}{l}\text { N/A (manual flow } \\
\text { switching) }\end{array}$ & $\begin{array}{l}\text { PMMA, glass } \\
\text { and SU-8 }\end{array}$ & Waveguides & No sheath & $\begin{array}{l}\text { Fu et al } \\
(1999,2002,2004)\end{array}$ \\
\hline Dielectrophoresis & $\begin{array}{l}\text { Dielectrophoretic cell } \\
\text { trapping and release }\end{array}$ & Syringe pump & $\begin{array}{l}\mathrm{N} / \mathrm{A} \text { (manual } \\
\text { cell sorting) }\end{array}$ & $\begin{array}{l}\text { Titanium, gold, } \\
\text { SU-8, glass }\end{array}$ & N/A & No sheath & $\begin{array}{l}\text { Voldman et al } \\
\text { (2002) }\end{array}$ \\
\hline $\begin{array}{l}\text { Electrowetting-assisted } \\
\text { flow switching }\end{array}$ & $\begin{array}{l}\text { Redirection of sample } \\
\text { streams by reversible } \\
\text { surface energy change }\end{array}$ & $\begin{array}{l}\text { Syringe and } \\
\text { vacuum pumps }\end{array}$ & $\begin{array}{l}25 \text { events of } \\
\text { switching s }{ }^{-1}\end{array}$ & $\begin{array}{l}\text { Teflon, ITO, } \\
\text { Silicon oxide, glass } \\
\text { and PDMS }\end{array}$ & N/A & Air & $\begin{array}{l}\text { Huh et al } \\
(2002,2003)\end{array}$ \\
\hline
\end{tabular}



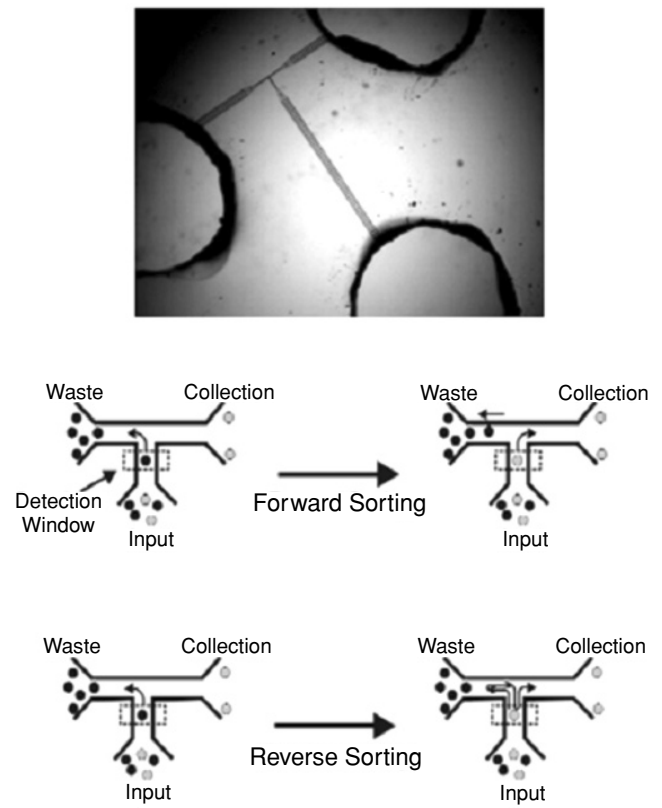

(a)
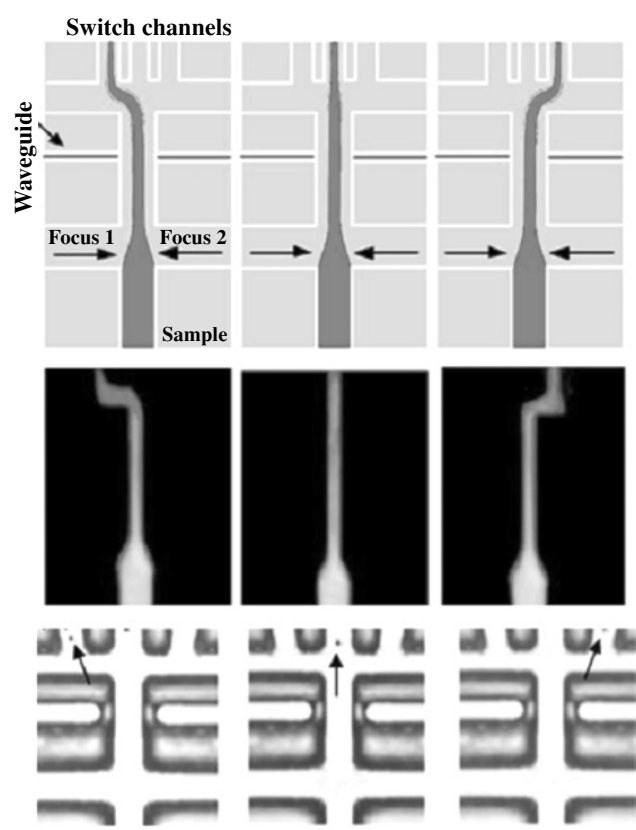

(b)

Figure 6. Microfabricated fluorescence-activated cell sorters based on electrokinetic switching of liquid streams. (a) In a microfabricated low chamber made of PDMS (top), a stream of cells or particles proceeding from input to waste is electrokinetically switched to flow to a collection port when fluorescence from labeled samples is detected near the T-shaped junction. (b) Sorting is achieved by lateral switching of an electrokinetic flow driven perpendicular to a sample stream, causing particulate samples (indicated by arrows in the bottommost insert) to flow into different outlet channels. Reprinted with permission from Fu et al (1999).

Fu et al (1999) presented the disposable fluorescence-activated cell sorting of microbeads and bacterial cells in a microfluidic device fabricated using soft lithography. The device consists of three microchannels joined at a T-shaped junction in which an electro-osmotic flow of sample particles advancing through a vertical input channel is diverted to a horizontal waste or collection channel (figure 6(a)). Fluid flows inside the channel are precisely controlled by an electric field applied to inlet, waste and collection ports in a rapid manner. The system does not use sheath flows or hydrodynamic focusing, but rather uses very small diameter channels and modest flow rates, keeping cells in focus and minimizing fluid mechanical stresses on the cells. When a fluorescently labeled cell is detected in the input channel, the sample stream flowing from an inlet to a waste port is quickly switched by reversed electric field to change its flow direction to a collection port, selectively delivering fluorescently labeled target particles to a sample collector. Using this fluidic switching-based sorting technique, they demonstrated sorting of fluorescent microbeads and E. coli at a throughput of $\sim 10$ beads $\mathrm{s}^{-1}$ and $\sim 20$ cells $\mathrm{s}^{-1}$. This system was further modified to have integrated pneumatically actuated components fabricated using multilayer soft lithography (Fu et al 2002). The sorter is incorporated with different microfluidic components such as peristaltic pumps, dampers, input/output wells and switch valves, enabling self-contained and automated cell trapping and sorting at higher throughputs (26-44 cells s $\left.{ }^{-1}\right)$.

An electrokinetic microfluidic system integrated with embedded optical waveguides made of glass and photoresist for on-chip sample detection and sorting has also been developed 


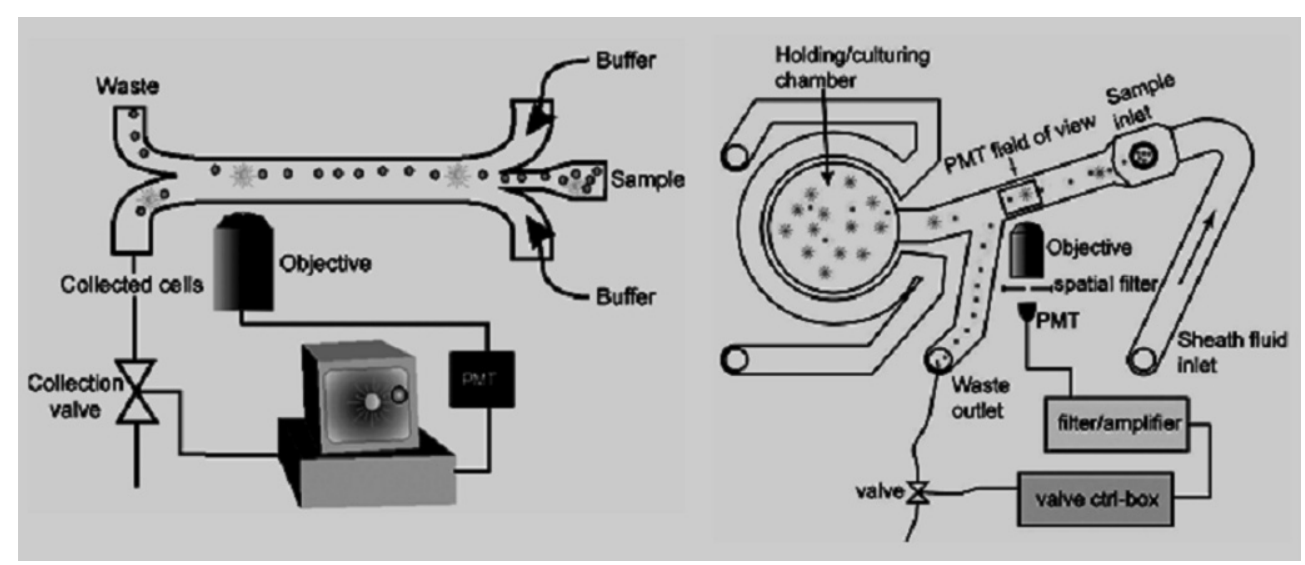

(a)

(b)

Figure 7. Microfabricated cell sorting device with advanced cell handling functionalities. (a) Simple sorting of detected cells (asterisks) is achieved by high-speed hydrodynamic valving at the collection channel, causing the sample stream flowing to waste to redirect to a collection port. (b) A similar fluidic valving-based sorting system is integrated with a cell culture chamber that allows continuous feeding of fresh media and culturing of collected cells (asterisks). Reprinted with permission from Wolff et al (2003).

(Fu et al 2004). Using multiple straight channels intersecting one another, the fluidic system permits the formation of an electrokinetically and hydrodynamically focused thin stream of cells/particles and simple sorting of particle samples through electrokinetic switching that redirects the focused sample stream in the center to different side outlets (figure 6(b)). The performance of this system was assessed by optical detection and sorting of microbeads and red blood cells using optics combined with avalanche photodetector, a gas laser and optical fibers.

Kruger et al (2002) used pressure-driven flow systems to manipulate sample streams in an X- or T-shaped junction by hydrodynamic switching. In the X-shaped device, as a liquid sample stream hydrodynamically focused along the center of an input channel approaches an X-shaped junction, a small amount of liquid is injected into or withdrawn from the side stream along a switch channel, causing the focused sample stream to deflect and flow into a collection channel. In the T-shaped device, a sample stream flowing from an input channel to waste is valved off at the waste port when particles of interest are observed, and the flow is redirected to a collection channel, isolating sample particles at the collection port. For sample detection, they integrated a laser diode and avalanche photodiode chips with high gain and selective optical filter coatings, and characterized the integrated optics through optical detection of flowing fluorescent microbeads.

Wolff et al (2003) developed a new type of pressure-driven microfabricated fluorescenceactivated cell sorter with advanced functional components such as cell culture systems and monolithically integrated waveguides. They achieved high-throughput $\left(\sim 12000\right.$ cells s $\left.^{-1}\right)$ analysis of chicken red blood cells with potential sorting capabilities of $\sim 200$ cells $\mathrm{s}^{-1}$, in which a hydrodynamically focused thin stream of cells originally flowing into a waste channel is rapidly switched to enter a collection port upon sample detection by using high-speed valving (response time of $2.5 \mathrm{~ms}$ ) of the collection microchannel (figure 7(a)). A similar hydrodynamic switching scheme was used for cell sorting in a second-generation device shown in figure 7(b). In this closed fluidic system, injected cells are confined to a thin stream by hydrodynamic 


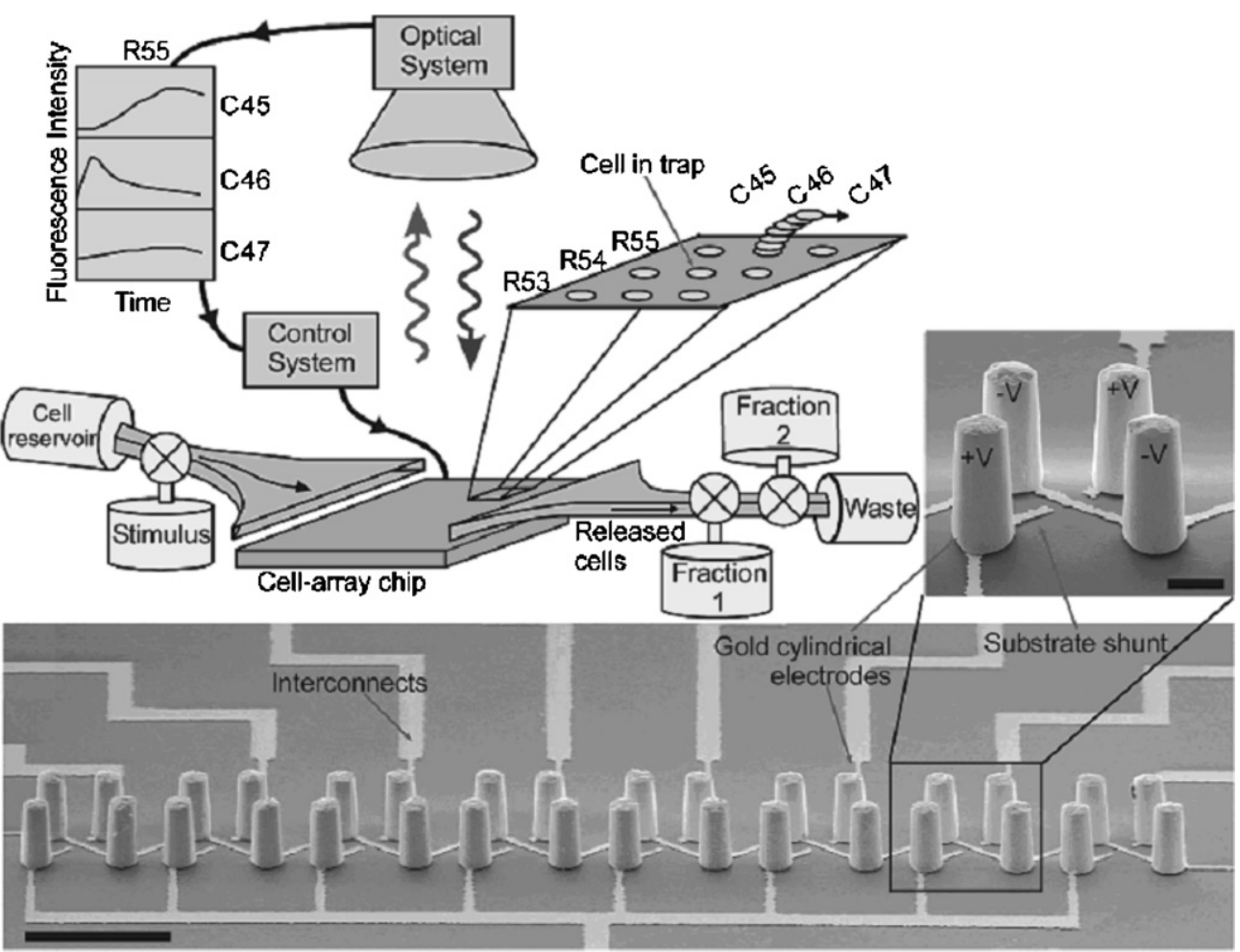

Figure 8. Dielectrophoresis-based cell trapping and sorting system. Selective immobilization of single cells is achieved using an array of quadrupole dielectrophoresis traps where an applied electric field generates a cellular dipole moment that repels the cell from the electric field and causes the cell to be trapped at the quadrupole's field minimum. Sorting is performed based on the observation of trapped cells using video microscopy and switching of ndividual electrodes (experimental setup of detection and sorting is shown in top insert). Reprinted with permission from Voldman et al (2002).

focusing and subsequently pass through a sensing area for optical detection. Detected cells of interest continue to flow into a culture chamber, whereas unnecessary cells are driven into waste by high-speed valving of the waste port. Microfluidic cell culture in the channel system with continuous feeding of fresh media was demonstrated by growing yeast cells sorted into the culture chamber. Integrated waveguides connected to a photomultiplier tube and a laser enabled high-speed $\left(\sim 1400\right.$ beads $\left.s^{-1}\right)$ detection of different subpopulations in a mixture of microbeads having varying amounts of fluorochromes.

Voldman et al (2002) introduced an innovative system for single-cell assays and sorting using arrays of dielectrophoretic traps. The microfabricated planar electrode array is individually addressable and has a novel asymmetric extruded-quadrupole geometry that can dielectrophoretically trap and hold single cells against fluid flows for assays and arbitrary sorting (figure 8). In operation, cells flowing over the array are captured by electrodes in a non-contact manner and a stimulus is then injected into the system to functionally label trapped cells. Fluorescence emanating from the cells is detected and recorded by a CCD camera-based optical system. By individually switching electrodes, selected subpopulations of cells can remain trapped or be released from the trap based on the fluorescence information obtained. To ensure each trap confines only one cell, they adjust the flow rate of liquid stream 


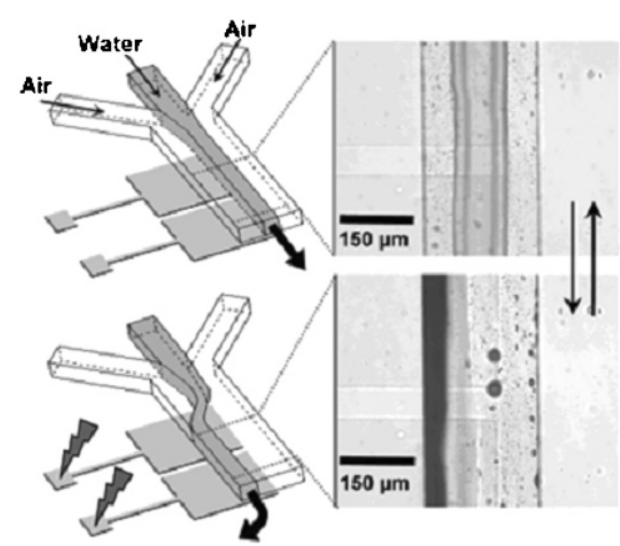

(a)

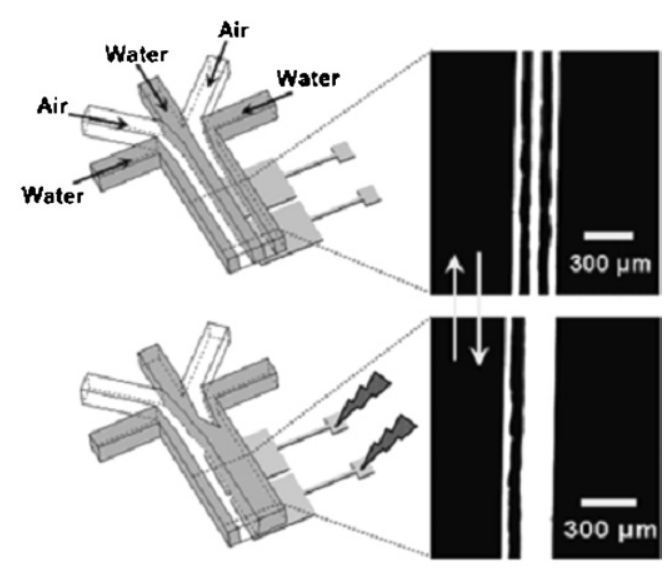

(b)

Figure 9. Rapid switching of air-liquid two-phase flow patterns using electrical modulation of surface wettability in PDMS microfluidic channels. (a) Repositioning of a centered high-speed liquid stream to the left sidewall is achieved by selectively making the left portion of a microchannel floor hydrophilic by the application of an electric field to the embedded electrodes. (b) In the system with three liquid streams separated by two air flows, similar manipulation of surface energy allows the middle liquid stream to merge with and subsequently separate from the rightmost liquid column. Reprinted with permission from Huh et al (2003).

against trapped cells so that the potential energy well is distorted and additional cells in the trap loaded with more than one cell are ejected. Successful loading, capture and sorting of labeled HL-60 cells were performed manually in multiple steps. They also performed in situ labeling and assay of trapped HL-60 cells using calcein and sorting of two different HL-60 cell populations by rapid and selective switching of individual traps.

Although the actual sorting of cells or particles has not been demonstrated, the airsheath flow cytometer developed by Huh et al (2002) was further improved to have the capability of manipulating the movement of thin liquid streams via electrical modulation of surface wetting property, known as electrowetting (Huh et al 2003). Electric potential applied to electrodes embedded in a channel wall instantaneously makes that surface hydrophilic. Through the rapid switching of wettability in a selected region of the inner channel surface, an appropriately positioned and aerodynamically focused liquid streams experience driving forces that generate lateral movement, prompting the liquid streams to rapidly reposition to the sidewall or to merge (figure 9). This system enables reversible positioning of high-speed (up to several $\mathrm{m} \mathrm{s}^{-1}$ ) liquid streams, opening a new way to incorporate structurally simple sorting mechanisms that have no moving parts into air-sheath flow cytometers.

\section{Other microfluidic cell separation/analysis systems}

In addition to cytometric analysis of cells using high-speed flow and fluorescence/ luminescence of labeled samples, there exist many other different and complementary methods to characterize and sort cells in microfluidic devices depending on chemical composition, motility, mechanical properties, electromagnetic properties, morphology, etc. When combined with flow cytometry, these systems have the potential to provide increased degree of quantitative measurements, permitting more detailed analysis of cell populations and the identification of multiple heterogeneities. 
When combined with cell lysis, separation and detection, high-throughput single-cell analysis in microfluidic devices can be useful for studying chemical composition and biological activity of single cells. McClain et al (2003) designed an integrated microfluidic device that can automatically transport cells to an electrical lysis chamber, inject the cell lysate into a separation channel, and electrophoretically separate labeled cellular contents that are detected by laserinduced fluorescence (LIF) optics. Single cells labeled with different kinds of fluorescent dyes that stain cytosolic contents are first lysed by applied high-strength AC electric field. The cell lysate is then transported by a pressure-driven flow to a separation channel where labeled lysate components in a horizontal channel are injected into a vertical separation channel and separated by applied electric field in an electrophoretic manner. Glass microchannel surfaces are coated with PDMS or other polymers to prevent adhesion of cells and suppress electroosmotic flow that disrupts electrophoretic separation. Using this system, they demonstrated a biochemical analysis of single Jurkat cells loaded with Oregon green and carboxyfluorescein based on electrophoretic separation and detection of cytosolic dyes released from individual cells. Rapid lysis of single cells and precise separation of labeled cellular contents enable more accurate and faster measurement of the concentrations of biochemical molecules compared to standard benchtop capillary electrophoresis systems.

Manipulation and analysis of single living cells in an integrated microfluidic device have been reported by Wheeler et al (2003). The complex microfluidic system combines fluidic pumping and valving based on multilayer soft lithography (Unger et al 2000) with biochemical assays of isolated single cells. Separation and isolation of single cells are achieved by fluidic control at a T-shaped microchannel junction in which a stagnation point created by the splitting of fluid flow into two streams allows single cells to land at the junction and be trapped inside a microfabricated dock structure (figure 10(a)). The dock is located close to a microchannel through which nanoliter volumes of reagents can be precisely delivered to a trapped cell. The operation of single-cell capture and subsequent perfusion of reagents onto the selected cell were demonstrated by a viability assay using trypan blue dye and a trapped live or dead Jurkat T-cell. Changes in intracellular calcium concentrations of trapped Jurkat T-cells or U937 cells (human monocytic cell line) labeled with calcium-indicating fluorescent dye were induced by perfusion of ionomycin or loading of primary and secondary antibodies. The concentrations were measured on an inverted microscope equipped with a laser and a photomultiplier tube to show transient increases in the calcium concentrations.

Arai et al (2001) developed a microfluidic system for manipulation and separation of single microbial cells using a combination of laser trapping and dielectrophoresis. Precise handling of single cells in a fluid stream is achieved by optically trapping a single target microbial cell at the focal point of a laser and by excluding unwanted cells from the trap via dielectrophoresis. The trapped target cell is carefully guided, by an automated visual feedback system, to a main fluidic channel by controlling the position of the focal point and released into a liquid stream transporting the cell to the extraction port. The proliferation of separated and collected yeast cells was shown, indicating that direct laser irradiation in laser trapping at least does not kill the analyzed cells.

The flow-based macroscopic separation of cells and particles collectively known as fieldflow fractionation (FFF) has been implemented in microfluidic analysis and separation of cells. Yang et al (1999) presented the combination of dielectrophoresis and gravitational FFF for separation of different mammalian cell populations using a microfabricated electrode system. The essential feature of the device lies in the differential levitation of different cell types due to dielectrophoresis and gravity. Depending on the dielectric and physical properties, cells are repelled by dielectrophoresis from energized microelectrodes and lifted up to an equilibrium height at which a dielectrophoretic force is balanced by a gravitational force. Subsequent 


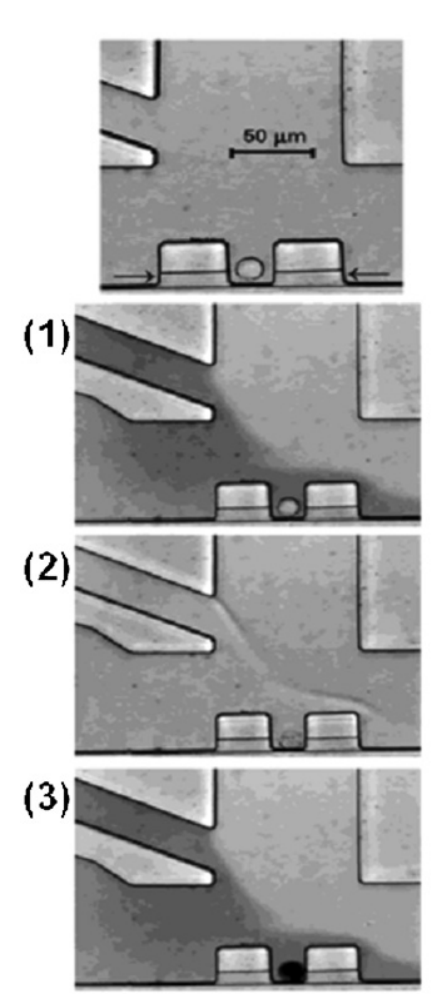

(a)

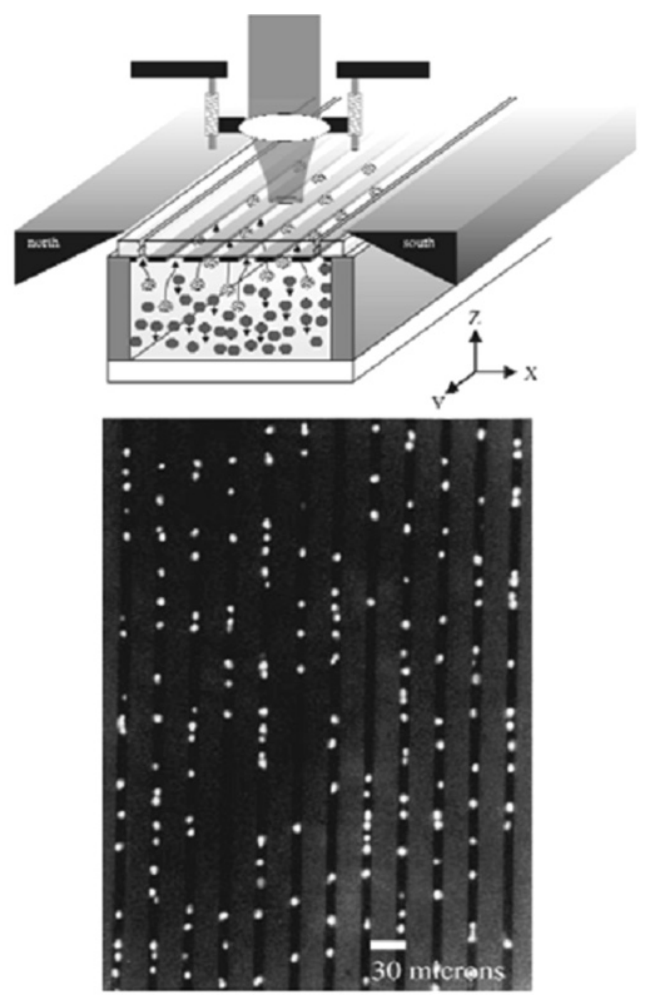

(b)

Figure 10. (a) Microfluidic single-cell manipulation and analysis system. A cell trapped in a microfabricated dock structure at the T-shaped (topmost) is analyzed using reagents delivered through another microchannel onto the cell. (1) A trapped cell is not labeled with trypan blue dye because it is viable. A dead cell perfused with methanol (2) is stained with trypan blue shown in (3). Reprinted with permission from Wheeler et al. (b) Immobilization and alignment of cells using a magnetic field. Cells incubated with ferromagnetic nanoparticles conjugated to antibodies are manipulated by a vertically applied magnetic field (top) to align between ferromagnetic Ni lines and the fluorescence is detected (bottom). Reprinted with permission from Tibbe et al (1999).

application of pressure-driven flow with a parabolic velocity profile results in transport of cells at different heights at different speed, permitting the sorting of different cell populations - the cells closer to the bottom wall move slower than those farther away from the wall due to the parabolic flow profile. Using a flow chamber having a microfabricated and interdigitated electrode array on the bottom surface, the separation of human breast cancer MDA-435 cells from normal blood cells was tested. Through careful adjustment of frequency and voltage applied to the electrodes as well as flow rate, they successfully separated MDA-435 cells with a short elution time from normal erythrocytes with a longer elution time within $5 \mathrm{~min}$.

An interesting approach based on magnetic beads-assisted alignment and separation of blood cells was reported by Tibbe et al (1999) (figure 10(b)). For separation of blood cells using a magnetic field, whole blood is incubated with ferromagnetic nanoparticles conjugated with antibodies. During this process, the cells expressing target surface antigen are coated with the magnetic particles and stained with fluorescent dyes. These target cells are then moved upward by an applied vertical magnetic gradient and aligned along microfabricated ferromagnetic Ni lines magnetized by an applied horizontal magnetic field. As a result of 
(a)
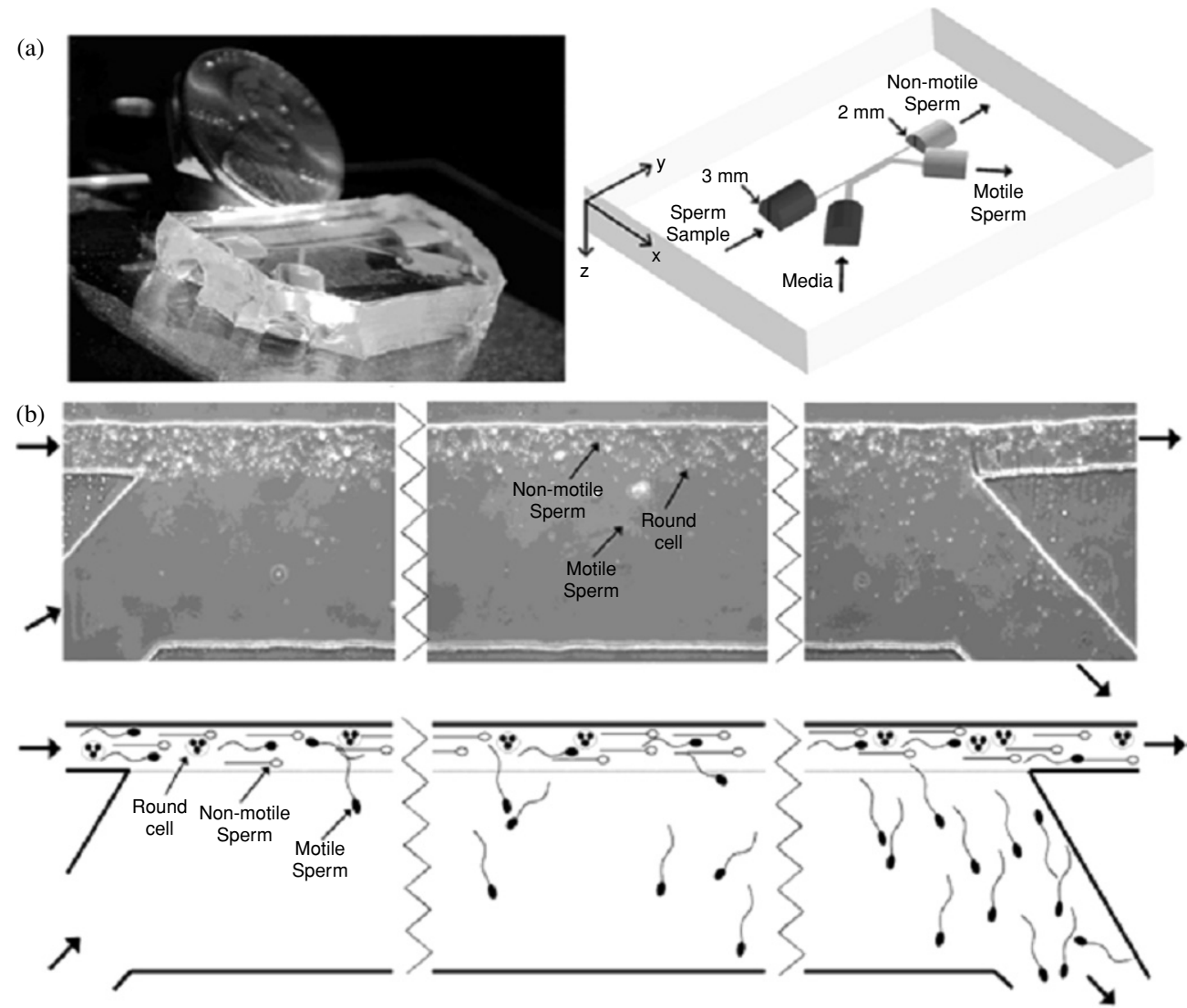

Figure 11. Microfluidic sperm sorter integrated with a passively driven pumping system. (a) The device consists of a main PDMS microchannel combined with horizontally oriented fluid reservoirs that generate steady liquid flows. (b) Sperm sorting is based on the ability of motile sperm confined to a thin laminar stream to swim out of their initial streamlines. Motile sperms are transported by another adjacent laminar stream and collected at the motile sperm collector. Reprinted with permission from Cho et al (2003).

the local magnetic gradient of these lines, nearby ferromagnetic labeled cells align between the lines, and the aligned cells are detected by compact-disk player optics combined with diode laser and photomultiplier tube. Using whole blood sample treated with CD45-labeled nanoparticles, allophycocyanin (APC)-labeled CD4 monoclonal antibodies and leukocyte staining Oxazine 750, the system was shown to be capable of identifying four different subpopulations including CD4+ lymphocytes, CD4+ monocytes, CD4- lymphocytes and granulocytes. Compared to other cell analysis systems, the immunomagnetic alignment technique uses simpler microfluidic systems and collects optical signals from cells for longer periods of time, permitting parallel analysis of cells with higher detection sensitivities and better signal-to-noise ratios.

Wilding et al have demonstrated mechanical filtration and isolation of cells followed by PCR analysis (Wilding et al 1998). They used microfabricated silicon 'weir-type' filters that allow only smaller and more deformable cells to pass through, enabling the separation and isolation of different sized cells in liquid streams. The weir-type filter system was integrated with a microfluidic chamber designed for PCR to amplify genomic DNA targets from isolated cells. A simple nucleic acid analysis was demonstrated by the isolation of white 
blood cells from whole blood sample and the amplification of a 202-bp sequence of exon 6 of the dystrophin gene taken directly from the genomic DNA of the filtered white blood cells. The yield of isolated cells in the system was more than sufficient for PCR of genomic targets, and capillary electrophoresis combined with a laser-induced fluorescence detection system successfully detected the 202-bp PCR product. The design of the microfabricated filter systems is readily modified to enable isolation of different cell types with varying size, shape and deformability.

Cho et al (2003) reported the development of a self-contained microfluidic system that can isolate motile sperm from non-motile sperm and other cellular debris in human semen sample. The mechanism of sorting is based on the active movement of motile sperm across adjacent steady laminar streams generated by a passively driven pumping system (Zhu et al 2004) that is integrated on-chip (figure 11). The purity of motile sperm after sorting was found to be almost $100 \%$ and approximately $40 \%$ of motile sperms introduced into the system were collected in the motile sperm outlet reservoir. Compared to conventional sorting techniques that require laborious and time-consuming manual process of finding viable sperm, this microfluidic system is self-contained, simple, inexpensive and efficient, opening new possibilities for use in clinical settings (Schuster et al 2003).

\section{Conclusion}

Flow cytometers are one of the earliest successes and the most useful instruments among microfluidic devices developed to date. In the past decade, microfluidic systems of flow cytometers have undergone rapid evolution spurred by two main factors: (i) the increased need for higher quality and larger quantity of cellular analysis data, and (ii) the enhanced sophistication and accessibility of microfabrication technologies. The emerging needs coupled with the new technical capabilities have led to a variety of exciting developments in microfluidics for flow cytometric analysis of cells and particles.

In addition to providing higher speeds, smaller sizes and lower costs, the use of microfabricated structures and microscale flow physics serves as an enabling technology to analyze and understand complex cellular processes at single-cell resolution in new ways that make use of the following advantages of microscale cellular analysis. (i) The typical size of microfabricated fluidic systems is comparable to that of cells and allows for more precise control over multiple variables in complex cellular microenvironments. (ii) The small dimensions of microfluidic systems increase the surface-to-volume ratio, enhance the rate of mass transfer, and allow use of significantly less reagent volumes and shorter reaction times in biochemical cell assays. (iii) Single cells or functional microscale objects can be mechanically or electrically manipulated in a non-invasive manner. (iv) Microfabrication processes offer the possibility of massively parallel configurations with very high throughputs using arrays of microfluidic channels. Integration of multiple microfluidic systems having different analytical functions is also possible.

The cell analysis systems described in this review exemplify some of these multipronged efforts to exploit the potentials of flexible microfluidics and microfabrication for bioanalytical lab-on-a-chip instrumentation. They also provide an outlook for new opportunities in microfluidic cellular analysis, two of which we note here. (i) The orderly characteristics of low-Reynolds number flows permit straightforward prediction and control of flow patterns and transport phenomena. This may allow different channel designs to effect novel maneuvering of liquid streams and the transport of cells with greater flexibility in microfabricated flow cytometers. One of the recent trends has also seen the use of different fluids or combinations of fluids (e.g. gas, liquid, immiscible liquids, viscoelastic 
liquids, etc), coupled with unconventional driving forces for fluid flows (e.g. surface tension, electrokinetics, electrocapillarity, evaporation, etc). For example, even with relatively simple flow geometries, gas-liquid two-phase flows can display interesting nonlinear flow pattern changes that are triggered by modulating the surface energy of channel surfaces. These and other fluidic systems may be useful in the design of cell sorting systems where rapid and precise flow manipulation is required in a mechanically simple, overall compact and practical format. (ii) As is the case with conventional flow cytometers, increasing the number of measurement parameters is an important issue that needs to be pursued further in the development of microfabricated flow cytometry. A natural direction that one can envision would be to miniaturize and integrate optical systems that can detect multiple fluorescence colors, as already seen from several recent reports described in this review. Another potentially useful approach that is more unique for microfabricated systems would be the use of microfluidic devices capable of non-optical cellular analysis. Some examples that we have noted include impedance measurements of cells, motility-based cell sorting, mechanical filtration of cells and immobilization or isolation of cells based on electromagnetic properties. Future systems may also combine detection/quantification optics with some of these non-optical measurements. Such multi-parameter analysis using serially connected analytical microfluidic devices may be an interesting microfluidic alternative to the use of increasingly complicated optics.

Understanding cellular functions is one of the great opportunities and challenges in this post-genome era. As micro- and nanotechnologies are becoming more sophisticated and accessible, we believe that the best is yet to come in the development of novel microfluidic systems and powerful flow cytometers for innovative cellular investigations.

\section{Acknowledgments}

We thank the National Science Foundation (BES-0238625), the Whitaker Foundation, the Ralph E Powe Junior Faculty Award, the US Army Research Laboratory and the US Army Research Office (contract/grant no DAAD19-03-1-0168), and NIH for financial support.

\section{References}

Altendorf E, Zebert D, Holl M and Yager P 1997 Differential blood cell counts obtained using a microchannel based flow cytometer Transducers' 97 pp 531-4

Arai F, Ichikawa A, Ogawa M, Fukuda T, Horio K and Itoigawa K 2001 High-speed separation system of randomly suspended single living cells by laser trap and dielectrophoresis Electrophoresis 22 283-8

Boeck G 2001 Current status of flow cytometry in cell and molecular biology Int. Rev. Cytol. 204 239-98

Bohlen H, Schwenberg S, Bongaarts R and Pulak R 2004 Flow cytometry for isolation and optical analysis of embryoid bodies from cultured mouse embryonic stem cells 2nd Ann. Meeting of International Society of Stem Cell Researchers

Cabuz E, Schwichtenberg J, DeMers B, Satren E, Padmanabhan A and Cabuz C 2002 MEMS-based flow controller for flow cytometry Proc. Hilton Head 2002: Solid-State Sensor, Actuator and Microsystems Workshop pp 110-1

Chan S D H, Luedke G, Valer M, Buhlmann C and Preckel T 2003 Cytometric analysis of protein expression and apoptosis in human primary cells with a novel microfluidic chip-based system Cytometry A 55 119-25

Chau L-K, Osborn T, Wu C-C and Yager P 1999 Microfabricated silicon flow-cell for optical monitoring of biological fluids Anal. Sci. 15 721-4

Cho B S, Schuster T G, Zhu X, Chang D, Smith G D and Takayama S 2003 Passively driven integrated microfluidic system for separation of motile sperm Anal. Chem. 75 1671-5

Chung S, Park S J, Kim J K, Chung C, Han D C and Chang J K 2003 Plastic microchip flow cytometer based on 2and 3-dimensional hydrodynamic flow focusing Microsyst. Technol. 9 525-33

Crissman H A, Darzynkiewicz Z, Tobey R A and Steinkamp J A 1985 Correlated measurements of DNA, RNA, and protein in individual cells by flow-cytometry Science 228 1321-4 
Crissman H A, Van Egmond J, Holdrinet R S, Pennings A and Haanen C 1981 Simplified method for DNA and protein staining of human hematopoietic-cell samples Cytometry 2 59-62

Darzynkiewicz Z, Bedner E, Li X, Gorczyca W and Melamed M R 1999 Laser-scanning cytometry: a new instrumentation with many applications Exp. Cell Res. 249 1-12

Dubelaar G B J and Gerritzen P L 2000 CytoBuoy: a step towards using flow cytometry in operational oceanography Sci. Mar. 64 255-65

Dubelaar G B J, Gerritzen P L, Beeker A E R, Jonker R R and Tangen K 1999 Design and first results of CytoBuoy: a wireless flow cytometer for in situ analysis of marine and fresh waters Cytometry 37 247-54

Duffy D C, McDonald J C, Schueller O J A and Whitesides G M 1998 Rapid prototyping of microfluidic systems in poly(dimethylsiloxane) Anal. Chem. 70 4974-84

Duijndam W A and Can Duijn P 1988 Flow cytometric determination of carbohydrates in human erythrocytes Histochemistry $\mathbf{8 8} 263-65$

Effenhauser C S, Harttig H and Kramer P 2004 An evaporation-based disposable micropump concept for continuous monitoring applications Biomed. Microdevices 4 27-32

Fenili D and Pirovano B 1998 The automation of sediment urinalysis using a new urine flow cytometer (UF-100 (TM)) Clin. Chem. Lab. Med. 36 909-17

Ferris M M, McCabe M O, Doan L G and Rowlen K L 2002 Rapid enumeration of respiratory viruses Anal. Chem. 74 1849-56

Fornas O, Domingo J C, Marin P and Petriz J 2002 Flow cytometric-based isolation of nucleated erythroid cells during maturation: an approach to cell surface antigen Cytometry 50 305-12

Fu A Y, Chou H-P, Spence C, Arnold F H and Quake S R 2002 An integrated microfabricated cell sorter Anal. Chem. 74 2451-7

Fu A Y, Spence C, Scherer A, Arnold F H and Quake S R 1999 A microfabricated fluorescence-activated cell sorter Nat. Biotechnol. 17 1109-11

Fu L-M, Yang R-J, Lin C-H, Pan Y-J and Lee G-B 2004 Electrokinetically driven micro flow cytometers with integrated fiber optics for on-line cell/particle detection Anal. Chim. Acta 507 163-9

Futai N, Gu W and Takayama S 2004 Rapid prototyping of microstructures with bell-shaped cross-sections and its application to deformation-based microfluidic valves Adv. Mater. 16 1320-3

Gabriel H and Kindermann W 1995 Flow-cytometry-principles and applications in exercise immunology Sports Med. 20 302-20

Garratty G and Arndt P A 1999 Applications of flow cytofluorometry to red blood cell immunology Cytometry 38 259-67

Gawad S, Schild L and Renaud Ph 2001 Micromachined impedance spectroscopy flow cytometer for cell analysis and particle sizing Lab. Chip 1 76-82

Goix P J 2004 Method and apparatus for detecting microparticles in fluid samples US Patent no 6710871

Gray J W, Carrano A V, Steinmetz L L, Vandilla M A, Moore D H, Mayall B H and Mendelsohn M L 1975 Chromosome measurement and sorting by flow systems Proc. Natl Acad. Sci. USA 72 1231-4

Gray J W, Dean P N, Fuscoe J C, Peters D C, Trask B J, Vandenengh G J and Vandilla M A 1987 High-speed chromosome sorting Science 238 323-29

Gray D W R, Gohde W, Carter N, Heiden T and Morris P J 1989 Separation of pancreatic islets by fluorescenceactivated sorting Diabetes $\mathbf{3 8} 133-5$

Gu W, Zhu X, Futai N, Cho B and Takayama S 2004 Computerized microfluidic cell culture using elastomeric channels and Braille displays Proc. Natl Acad. Sci. USA 101 15861-6

Harding C L, Lloyd D R, McFarlane C M and Al-Rubeai M 2000 Using the microcyte flow cytometer to monitor cell number, viability, and apoptosis in mammalian cell culture Biotechnol. Prog. 16 800-2

Hassall D G 1992 Three probe flow cytometry of a human foam-cell forming macrophage Cytometry 13 381-8

Hassall D G and Graham A 1995 Changes in free-cholesterol content, measured by filipin fluorescence and flowcytometry, correlate with changes in cholesterol-biosynthesis in THP-1 macrophage 1995 Cytometry 21 352-62

Horan P K and Wheeless L L 1977 Quantitative single cell analysis and sorting Science 198 149-57

Huh D, Tkaczyk A H, Bahng J H, Chang Y, Wei H-H, Grotberg J B, Kim C-J, Kurabayashi K and Takayama S 2003 Reversible switching of high-speed air-liquid two-phase flows using electrowetting-assisted flow-pattern change J. Am. Chem. Soc. $12514678-9$

Huh D, Tung Y-C, Wei H-H, Grotberg J B, Skerlos S J, Kurabayashi K and Takayama S 2002 Use of air-liquid two-phase flow in hydrophobic microfluidic channels for disposable flow cytometers Biomed. Microdevices 4 141-9

Jett J H, Stevenson A P, Warner N L and Leary J F 1981 Quantitation of cell-surface antigen density by flow-cytometry Acta Pathol. Microbiol. Scand. A 274 215-21 
Kruger J, Singh K, O'Neill A, Jackson C, Morrison A and O'Brien P 2002 Development of a microfluidic device for fluorescence activated cell sorting J. Micromech. Microeng. 12 486-94

Lee G-B, Hung C-I, Ke B-J, Huang G-R, Hwei B-H and Lai H-F 2001 Hydrodynamic focusing for a micromachined flow cytometer Trans. ASME I 123 672-9

Lee G-B, Lin C-H and Chang G-L 2003 Micro flow cytometers with buried SU-8/SOG optical waveguides Sensors Actuator A 103 165-70

Maczek C, Recheis H, Bock G, Stulnig T, Jurgens G and Wick G 1996 Comparison of low density lipoprotein uptake by different human lymphocyte subsets: a new method using double-fluorescence staining J. Lipid Res. 37 $1363-71$

Madou M J 2002 Fundamentals of Microfabrication 2nd edn (Boca Raton, FL: CRC Press)

McClain M A, Culbertson C T, Jacobson S C, Allbritton N L, Sims C E and Ramsey J M 2003 Microfluidic devices for the high-throughput chemical analysis of cells Anal. Chem. 75 5646-55

McClain M A, Culbertson C T, Jacobson S C and Ramsey J M 2001 Flow cytometry of Escherichia coli on microfluidic devices Anal. Chem. 73 5334-8

Meuwis K, Boens N, Deschryver F C, Gallay J and Vincent M 1995 Photophysics of the fluorescent K+ indicator PBFI Biophys. J. 68 2469-73

Minta A and Tsien R Y 1989 Fluorescent indicators for cytosolic sodium J. Biol. Chem. 264 19449-57

Miyake R, Ohki H, Yamazaki I and Takagi T 1997 Investigation of sheath flow chambers for flow cytometers (micro machined flow chamber with low pressure loss) JSME Int. J. B 40 106-13

Niehren S, Kinzelbach W, Seeger S and Wolfrum J 1995 An all-solid-state flow cytometer for counting fluorescent microspheres Anal. Chem. 67 2666-71

Peters D, Branscomb E, Dean P, Merrill T, Pinkel D, Vandilla M and Gray J W 1985 The LLNL high-speed sorter-design-features, operational characteristics, and biological utility Cytometry 6 290-301

Roederer M, DeRosa S, Gerstein R, Anderson M, Bigos M, Stovel R, Nozaki T, Parks D, Herzenberg L and Herzenberg L 19978 color, 10-parameter flow cytometry to elucidate complex leukocyte heterogeneity Cytometry 29 328-39

Schuster T G, Cho B, Keller L M, Takayama S and Smith G D 2003 Isolation of motile sperm from semen samples using microfluidics Reprod. Biomed. Online 7 75-81

Shapiro H M 1995 Practical Flow Cytometry (New York: Wiley-Liss)

Snow C 2003 Flow cytometer electronics Cytometry A 57 63-9

Sobek D, Young A M, Gray M L and Senturia S D 1993 Microfabricated fused silica flow chambers for flow cytometry Proc. IEEE 2 219-24

Stein D S, Korvick J A and Vermund S H 1992 CD4+ lymphocyte cell enumeration for prediction of clinical course of human-immunodeficiency-virus disease-A review J. Infect. Dis. 165 352-63

Steinkam J A, Fulwyler M J, Coulter J R, Hiebert R D, Horney J L and Mullaney P F 1973 New multiparamter separator for microscopic particles and biological cells Rev. Sci. Intrum. 44 1301-10

Stone H A, Stroock A D and Ajdari A 2004 Engineering flows in small devices: Microfluidics toward a lab-on-a-chip Annu. Rev. Fluid Mech. 36 381-411

Streicher J, Valent P, Schmidt H, Sengolge G, Wagner O, Strobl W, Horl WH and Derfler K 1999 Up-regulation of LDL-receptor expression by LDL-immunoapheresis in patients with familial hypercholesterolemia J. Invest. Med. $47378-87$

Tibbe A G J, de Grooth B G, Greve J, Liberti P A, Dolan G J and Terstappen L W M M 1999 Optical tracking and detection of immunomagnetically selected and aligned cells Nat. Biotechnol. 17 1210-3

Tung Y-C, Zhang M, Lin C-T, Kurabayashi K and Skerlos S J 2004 PDMS-based opto-fluidic micro flow cytometer with two-color, multi-angle fluorescence detection capability using PIN photodiodes Sensors Actuators B 98 356-67

Unger M A, Chou H P, Thorsen T, Scherer A and Quake S R 2000 Monolithic microfabricated valves and pumps by multilayer soft lithography Science $\mathbf{2 8 8} 113-6$

Voldman J, Gray M L, Toner M and Schmidt M A 2002 A microfabrication-based dynamic array cytometer Anal. Chem. 74 3984-90

Walker G M and Beebe D J 2002 A passive pumping method for microfluidic devices Lab. Chip 2 131-4

Wedemeyer N and Potter T 2001 Flow cytometry: an 'old' tool for novel applications in medical genetics Clin. Genet. 60 1-8

Weigl B H, Bardell R, Schulte T, Battrell F and Hayenga J 2001 Design and rapid prototyping of thin-film laminatebased microfluidic devices Biomed. Microdevices 3 267-74

Wheeler A R, Throndset W R, Whelan R J, Leach A M, Zare R N, Liao Y H, Farrell K, Manger I D and Daridon A 2003 Microfluidic device for single-cell analysis Anal. Chem. 75 3581-6 
Whitesides G M, Ostuni E, Takayama S, Jiang X and Ingber D E 2001 Soft lithography in biology and biochemistry Annu. Rev. Biomed. Eng. 3 335-73

Wilding P, Kricka L J, Cheng J, Hvichia G, Shoffner M A and Fortnia P 1998 Integrated cell isolation and polymerase chain reaction analysis using silicon microfilter chambers Anal. Biochem. 257 95-100

Wolff A, Perch-Nielsen I R, Larsen U D, Friis P, Goranovic G, Poulsen C R, Kutter J P and Telleman P 2003 Integrating advanced functionality in a microfabricated high-throughput fluorescent-activated cell sorter $L a b$. Chip $322-7$

Yang X, Grosjean C, Tai Y-C and Ho C-M 1998 A MEMS thermopneumatic silicon rubber membrane valve Sensors Actuators A 64 101-8

Yang J, Huang Y, Wang X-B, Becker F F and Gascoyne R C 1999 Cell separation on microfabricated electrodes using dielectrophoresis/gravitational field-flow fractionation Anal. Chem. 71 911-8

Zhong C F, Ye J Y, Myc A, Cao Z, Kukowska J, Baker J R and Norris T B 2003 In vivo flow cytometry Optical Society of America 2003

Zhu X, Chu L Y, Chueh B-H, Shen M, Hazarika B, Phadke N and Takayama S 2004 Arrays of horizontally-oriented mini-reservoirs generate steady microfluidic flows for continues perfusion cell culture and gradient generation Analyst 129 1-6 